\title{
Differential heat sensitivity of two cool-season legumes, chickpea and lentil, at the reproductive stage, is associated with responses in pollen function, photosynthetic ability and oxidative damage
}

\author{
Kalpna Bhandari ${ }^{1}$ | Kumari Sita ${ }^{1}$ | Akanksha Sehgal ${ }^{1, *}$ | Anjali Bhardwaj ${ }^{1}$ | \\ Pooran Gaur $^{2}$ | Shiv Kumar ${ }^{3}$ | Sarvjeet Singh ${ }^{4}$ | Kadambot H. M. Siddique ${ }^{5}$ | \\ P. V. Vara Prasad ${ }^{6}$ (D) | Uday Jha ${ }^{7}$ Harsh Nayyar ${ }^{1}$ (D)
}

${ }^{1}$ Department of Botany, Panjab University, Chandigarh, India

${ }^{2}$ ICRISAT, Hyderabad, Telangana, India

${ }^{3}$ ICARDA, Rabat, Morocco

${ }^{4}$ Punjab Agricultural University, Ludhiana, India

${ }^{5}$ The UWA Institute of Agriculture,

University of Western Australia, Perth, WA, Australia

${ }^{6}$ Kansas State University, Manhattan, KS, USA

${ }^{7}$ Indian Institute of Pulses Research, Kanpur, India

Correspondence

Harsh Nayyar, Department of Botany,

Panjab University, Chandigarh 160014,

India.

Email: harshnayyar@hotmail.com

*Present address

Akanksha Sehgal, Department of Plant and Soil Sciences, Mississippi State University,

Mississippi, MS, USA

Funding information

DST, India; ICARDA Morocco; University of Western Australia

\begin{abstract}
Increasing temperatures are adversely affecting various food crops, including legumes, and this issue requires attention. The growth of two cool-season food legumes, chickpea and lentil, is inhibited by high temperatures but their relative sensitivity to heat stress and the underlying reasons have not been investigated. Moreover, the high-temperature thresholds for these two legumes have not been well-characterised. In the present study, three chickpea (ICCVO7110, ICC5912 and ICCV92944) and two lentil (LL699 and LL931) genotypes, having nearly similar phenology with respect to flowering, were grown at $30 / 20^{\circ} \mathrm{C}$ (day/night; control) until the onset of flowering and subsequently exposed to varying high temperatures (35/25, 38/28, 40/30 and $42 / 32^{\circ} \mathrm{C}$; day/night) in a controlled environment (growth chamber; $12 \mathrm{hr} / 12 \mathrm{hr}$; light intensity $750 \mu \mathrm{mol} \mathrm{m} \mathrm{m}^{-2} \mathrm{~s}^{-1}$ : RH-70\%) at 108 days after sowing for both the species. Phenology (podding, maturity) was accelerated in both the species; the days to podding declined more in lentil at $35 / 25$ (2.8 days) and $38 / 28^{\circ} \mathrm{C}$ (11.3 days) than in chickpea (1.7 and 7.1 days, respectively). Heat stress decreased flowering-podding and podding-maturity intervals considerably in both the species. At higher temperatures, no podding was observed in lentil, while chickpea showed reduction of 14.9 and 16.1 days at $40 / 30$ and $42 / 32^{\circ} \mathrm{C}$, respectively. Maturity was accelerated on 15.3 and 12.5 days at $38 / 28^{\circ} \mathrm{C}, 33.6$ and 34 days at $40 / 30^{\circ} \mathrm{C}$ and 45.6 and 47 days at $42 / 32^{\circ} \mathrm{C}$, in chickpea and lentil, respectively. Consequently, biomass decreased considerably at $38 / 28^{\circ} \mathrm{C}$ in both the species to limit the yield-related traits. Lentil was significantly more sensitive to heat stress, with the damage-assessed as reduction in biomass, reproductive function-related traits (pollen viability, germination, pollen tube growth and stigma receptivity), leaf traits such as membrane injury, leaf water status, photochemical efficiency, chlorophyll concentration, carbon fixation and assimilation, and oxidative stress, appearing even at $35 / 25^{\circ} \mathrm{C}$, compared with $38 / 28^{\circ} \mathrm{C}$, in chickpea. The expression of enzymatic antioxidants such as superoxide dismutase, catalase, ascorbate peroxidase, glutathione reductase and non-enzymatic
\end{abstract}


antioxidants declined remarkably with heat stress, more so in lentil than in chickpea. Carbon fixation (assessed as Rubisco activity) and assimilation (assessed as sucrose concentration, sucrose synthase activity) were also reduced more in lentil than in chickpea, at all the stressful temperatures, resulting in more inhibition of plant biomass (shoot + roots), damage to reproductive function and severe reduction in pods and seeds. At $38 / 28^{\circ} \mathrm{C}$, lentil showed $43 \%$ reduction in biomass, while it declined by $17.2 \%$ in chickpea at the same time, over the control temperature $\left(30 / 20^{\circ} \mathrm{C}\right)$. At this temperature, lentil showed $53 \%$ and $46 \%$ reduction in pods and seed yield, compared to $13.4 \%$ and $22 \%$ decrease in chickpea at the same temperature. At $40 / 30^{\circ} \mathrm{C}$, lentil did not produce any pods, while chickpea was able to produce few pods at this temperature. This study identified that lentil is considerably more sensitive to heat stress than chickpea, as a result of more damage to leaves (photosynthetic ability; oxidative injury) and reproductive components (pollen function, etc.) at $35 / 25^{\circ} \mathrm{C}$ and above, at controlled conditions.

KEYWORDS

carbon fixation, high temperature, legumes, pollen, pulses, stress

\section{1 | INTRODUCTION}

Rising temperatures, both globally and locally, are resulting in heat stress for various summer- and cool-season food crops (Sehgal et al., 2018). Heat stress for most subtropical and tropical crops refers to situations where the temperature exceeds $32-35^{\circ} \mathrm{C}$ (maximum value; Bita \& Gerats, 2013); however, for cool-season crops, a daily maximum temperature more than $25^{\circ} \mathrm{C}$ (maximum value) is considered stressful (Wahid, Gelani, Ashraf, \& Foolad, 2007; Wardlaw \& Wrigley, 1994). The effect of heat stress varies depending on the temperature, duration of exposure and intensity (Wahid et al., 2007). Heat stress accelerates phenology and causes a significant decline in vegetative and reproductive duration (pod and seed number, seed filling) to inhibit the potential yields, as reported in various crops (Annisa, Chen, Turner, \& Cowling, 2013; Bita \& Gerats, 2013; Zhou, Kjaer, Rosenqvist, Yu, \& Ottosen, 2016). Heat stress causes several changes at various organisational levels to inhibit vegetative and reproductive stages of plants (Hasanuzzaman, Nahar, Alam, Roychowdhury, \& Fujita, 2013; Stone, 2001). Heat stress disrupts various physiological processes such as photosynthesis, carbon fixation and assimilation (Awasthi et al., 2014), impairs electron transport (Sharma, Andersen, Ottosen, \& Rosenqvist, 2015) and causes leaf dehydration due to water loss and stomatal closure (Sita, Sehgal, HanumanthaRao, et al., 2017), inhibition of various enzymes (Yang, Gu, Ding, Lu, \& Lu, 2018) and alterations in antioxidant defence systems (Awasthi, Bhandari, \& Nayyar, 2015), which damage vegetative and reproductive development (Barnabás, Jäger, \& Fehér, 2008). The reproductive stage is found to be more sensitive to heat stress than the vegetative stage (Hasanuzzaman et al., 2013). Damage to reproductive processes is the result of damage to pollen and stigmatic functions (Giorno, Wolters-Arts, Mariani, \& Rieu, 2013) leading to poor pod set as well as fewer pods and seeds (Barnabás et al., 2008).

Food legumes, especially those adapted to cool-season environments, are highly sensitive to high temperature during the reproductive stage (Sita, Sehgal, HanumanthaRao, et al., 2017). Chickpea and lentil are two major cool-season legumes that have temperature optima between 15 and $30^{\circ} \mathrm{C}$ and grow best at temperatures less than $30 / 20^{\circ} \mathrm{C}$; higher temperatures markedly inhibit the production potential of these legumes (Devasirvatham, Gaur, Raju, Trethowan, \& Tan, 2015; Gaur et al., 2014). We have earlier reported the adverse impacts of heat stress on chickpea (Kumar et al., 2013; Kaushal et al., 2013) as well as lentil (Sita, Sehgal, Kumar, et al., 2017) but the relative sensitivity of these two legumes to heat stress has not been reported so far, which is important from academic and practical points of view. In the present study, we hypothesised that both the legume species would differ in their heat sensitivity and might have variation at high-temperature thresholds. Considering the above, the objectives of the present study were to (a) assess the high-temperature threshold for chickpea and lentil, and its impact on various reproductive and physiological traits, and (b) compare these two legumes at similar temperatures to determine their relative sensitivity to heat stress.

\section{2 | MATERIALS AND METHODS}

The seeds of genotypes of chickpea (ICCVO7110, ICC5912; experimental accessions, ICCV92944; a released variety [as JG14; relatively heat-tolerant]) were procured from International Crops Research Institute for Semi-Arid Tropics (ICRISAT), Hyderabad, 
TAB LE 1 Phenology of chickpea (CP) and lentil (LT) genotypes at different high temperatures

\begin{tabular}{|c|c|c|c|c|c|}
\hline & $30 / 20^{\circ} \mathrm{C}$ & $35 / 25^{\circ} \mathrm{C}$ & $38 / 28^{\circ} \mathrm{C}$ & $40 / 30^{\circ} \mathrm{C}$ & $42 / 32^{\circ} \mathrm{C}$ \\
\hline \multicolumn{6}{|l|}{ Days to flowering } \\
\hline CP-ICCV07110 & $106 \pm 1.9 \mathrm{Aa}$ & $106 \pm 1.9 \mathrm{Aa}$ & $106 \pm 1.9 \mathrm{Aa}$ & $106 \pm 1.9 \mathrm{Aa}$ & $106 \pm 1.9 \mathrm{Aa}$ \\
\hline CP-ICC5912 & $105 \pm 1.7 \mathrm{Ba}$ & $105 \pm 1.7 \mathrm{Aa}$ & $105 \pm 1.7 \mathrm{Aa}$ & $105 \pm 1.7 \mathrm{Aa}$ & $105 \pm 1.7 \mathrm{Aa}$ \\
\hline Mean & 104.6 & 104.6 & 104.6 & 104.6 & 104.6 \\
\hline LT-LL931 & $99 \pm 1.8 \mathrm{Cb}$ & $99 \pm 1.8 \mathrm{Cb}$ & $99 \pm 1.8 \mathrm{Cb}$ & $99 \pm 1.8 \mathrm{Cb}$ & $99 \pm 1.8 \mathrm{Cb}$ \\
\hline Mean & 98.5 & 98.5 & 98.5 & 98.5 & 98.5 \\
\hline \multicolumn{6}{|l|}{ Days to podding } \\
\hline CP-ICCV07110 & $126 \pm 1.7 \mathrm{Aa}$ & $124 \pm 1.7 \mathrm{Aa}$ & $115 \pm 1.8 \mathrm{Ba}$ & $111 \pm 1.8 \mathrm{Ba}$ & $110 \pm 1.9 \mathrm{Ba}$ \\
\hline CP-ICVV92944 & $125 \pm 1.9 \mathrm{Aa}$ & $124 \pm 1.9 \mathrm{Aa}$ & $118 \pm 1.9 \mathrm{Ba}$ & $109 \pm 1.9 \mathrm{Ba}$ & $108 \pm 1.8 \mathrm{Ba}$ \\
\hline LT-LL699 & $115 \pm 4.1 \mathrm{Bb}$ & $112 \pm 1.9 \mathrm{Bb}$ & $104 \pm 1.6 \mathrm{Cb}$ & 0 & 0 \\
\hline LT-LL931 & $116 \pm 4.2 \mathrm{Bb}$ & $114 \pm 1.7 \mathrm{Bb}$ & $106 \pm 1.2 \mathrm{Cb}$ & 0 & 0 \\
\hline Mean & 115.5 & 113 & 105 & 0 & 0 \\
\hline \multicolumn{6}{|l|}{ Days to maturity } \\
\hline CP-ICCV07110 & $148 \pm 1.7 A a$ & $143 \pm 1.8 \mathrm{Aa}$ & $135 \pm 1.9 \mathrm{Ba}$ & $116 \pm 1.8 \mathrm{Ca}$ & $106 \pm 1.7 \mathrm{Ca}$ \\
\hline CP-ICVV92944 & $151 \pm 1.9 \mathrm{Aa}$ & $147 \pm 1.9 \mathrm{Aa}$ & $134 \pm 1.7 \mathrm{Ba}$ & $117 \pm 1.9 \mathrm{Ca}$ & $104 \pm 1.9 \mathrm{Ca}$ \\
\hline CP-ICC5912 & $152 \pm 1.6 \mathrm{Aa}$ & $148 \pm 1.8 \mathrm{Aa}$ & $136 \pm 1 \mathrm{Ba}$ & $117 \pm 1.5 \mathrm{Ca}$ & $108 \pm 1.6 \mathrm{Ca}$ \\
\hline Mean & 150.3 & 146 & 135 & 116.6 & 106 \\
\hline LT-LL699 & $134 \pm 1.9 \mathrm{Bb}$ & $129 \pm 1.8 \mathrm{Bb}$ & $120 \pm 1.9 \mathrm{Cb}$ & $99 \pm 1.5 \mathrm{Db}$ & $84 \pm 1.8 \mathrm{~Eb}$ \\
\hline CP-ICC5912 & 21 & 19.6 & 6.6 & 5.6 & 3.25 \\
\hline LT-LL699 & $17 \pm 1.3 \mathrm{Bb}$ & $14 \pm 1.8 \mathrm{Cb}$ & $6 \pm 1.3 \mathrm{~Eb}$ & 0 & 0 \\
\hline LT-LL931 & $17 \pm 1.5 \mathrm{Bb}$ & $15 \pm 1.4 \mathrm{Cb}$ & $7 \pm 1.3 \mathrm{~Eb}$ & 0 & 0 \\
\hline Grand mean & 17 & 13.5 & 6.5 & 0 & 0 \\
\hline \multicolumn{6}{|c|}{ Podding-maturity interval } \\
\hline CP-ICCV07110 & $22 \pm 1.3 \mathrm{Ba}$ & $19 \pm 1.5 \mathrm{Ba}$ & $20 \pm 1.4 \mathrm{Ba}$ & $5 \pm 1.2 \mathrm{Fa}$ & $4 \pm 1.3 \mathrm{Fa}$ \\
\hline CP-ICVV92944 & $26 \pm 1.4 \mathrm{Aa}$ & $22 \pm 1.3 \mathrm{Ba}$ & $16 \pm 1.3 \mathrm{Ba}$ & $6 \pm 1.3 \mathrm{Fa}$ & $5 \pm 1.5 \mathrm{Fa}$ \\
\hline CP-ICC5912 & $26 \pm 1.6 \mathrm{Aa}$ & $23 \pm 1.6 \mathrm{Ba}$ & $16 \pm 1.7 \mathrm{Ba}$ & $6 \pm 1.5 \mathrm{Fa}$ & $4 \pm 1.2 \mathrm{Fa}$ \\
\hline Mean & 24.6 & 21.3 & 17.3 & 5.6 & 4.3 \\
\hline LT-LL699 & $19 \pm 1.6 \mathrm{Cb}$ & $15 \pm 1.4 \mathrm{Db}$ & $13 \pm 1.2 \mathrm{Db}$ & 0 & 0 \\
\hline LT-LL931 & $18 \pm 1.4 \mathrm{Cb}$ & $14 \pm 1.8 \mathrm{Db}$ & $12 \pm 1.1 \mathrm{DEb}$ & 0 & 0 \\
\hline Mean & 18.5 & 14.5 & 12.5 & 0 & 0 \\
\hline
\end{tabular}

Note: Mean values along with standard errors are presented. Heat stress $\left(35 / 25^{\circ} \mathrm{C}\right.$ onwards) was imposed at the time of onset of flowering; hence, the values for days to flowering are similar at all the temperatures. Different capital letters indicate significant differences $(p<.05)$ among genotypes of two species (as per nested ANOVA) across all the temperature treatments. Different small letters on bars indicate significant differences ( $p<.05$ ) between two species for a particular temperature. Measurements were recorded after 10 days of exposure to heat stress.

while those of lentil (LL699, LL931; released varieties; moderately resistant to pod borer and rust) were obtained from Punjab Agricultural University, Ludhiana, India. These were chosen on the basis of near-similarity in their phenology, especially with respect to flowering (Table 1). The seeds were treated with Rhizobium cultures specific for chickpea ( $R$. ciceri) and lentil ( $R$. leguminosarum) 
using $10 \%$ jaggery solution as an adhesive. The solution was spread over the seeds, followed by mixing to form a thin coating over the seeds. Rhizobium inoculants were added and mixed thoroughly with the seeds, followed by shade drying by spreading over the polysheet overnight, prior to sowing. Plants were raised from the treated seeds in soil given appropriate doses of farmyard manure and grown in pots ( $20 \mathrm{~cm}$ diameter; $7 \mathrm{~kg}$ capacity) in a controlled environment at $30 / 20^{\circ} \mathrm{C}$ (day/night; $12 \mathrm{hr} / 12 \mathrm{hr}$; light intensity $450 \mu \mathrm{mol} \mathrm{m}{ }^{-2} \mathrm{~s}^{-1} ; \mathrm{RH}-70 \%$ ), until the onset of flowering (about $98-$ 106 days after sowing in both the crop species). Thereafter, sets of the plants were grown in controlled environments at varying high temperatures of $35 / 25^{\circ} \mathrm{C}, 38 / 28^{\circ} \mathrm{C}, 40 / 30^{\circ} \mathrm{C}$ and $42 / 32^{\circ} \mathrm{C}$ (12 hr/12 hr; light intensity $750 \mu \mathrm{mol} \mathrm{m}{ }^{-2} \mathrm{~s}^{-1}$; RH-70\%), while one set was maintained at $30 / 20^{\circ} \mathrm{C}$ (control), until maturity. The plants were irrigated thrice (predawn, midday and evening time) to keep the soil fully hydrated to avoid drought stress. The atmospheric conditions (light, $\mathrm{RH}$ ) were maintained to the same levels with electronic controls, while irrigation was done manually. For each genotype, the plants (one per pot) were maintained in five replicated pots. The plants were tested for various reproductive, leaf and yield traits, as follows. Leaf damage and reproductive function were recorded after 10 days of stress, by collecting leaves and flowers at the same time. The stress was imposed from flowering to maturity, and the impact was assessed on yield components at maturity. Though chickpea (103-106 days after sowing) and lentil (98-99 days after sowing) flowered at different times, these were exposed to heat stress treatments at the same time (108 days after sowing for both the species) to maintain uniformity of exposure. For yield traits, a separate set of five pots having one plant each was maintained. No destructive leaf and flower assays were performed on these plants.

\section{1 | Stress injury to leaves}

After 10 days of exposure to heat stress (varying temperatures), the leaves (already present during stress during initiation of stress) were harvested at 11:00 hr from the second- or third-top branches of three plants per genotype (from different pots), grown under various treatments and assessed for various traits related to stress injury.

Membrane damage was measured as electrolyte leakage by washing the leaves with deionised water to remove any adherents or electrolytes on the leaf surface. The leaf tissue was placed in $10 \mathrm{ml}$ of deionised water in a glass vial and incubated at $25^{\circ} \mathrm{C}$ for $24 \mathrm{hr}$ using a rotary shaker. Subsequently, electrical conductivity (L1) of the solution was measured, followed by heating at $120^{\circ} \mathrm{C}$ in a water bath for $20 \mathrm{~min}$ and at equilibration thereafter at $25^{\circ} \mathrm{C}$. The final electrical conductivity (L2) was recorded. Membrane damage was defined as (L1/L2) $\times 100$, expressed as a percentage (Lutts, Kinet, \& Bouharmont, 1996).

Leaf water status was measured as relative leaf water content, as per the method of Barrs and Weatherley (1962). Leaves from second- and third-top branches were collected and weighed, before immersing them in distilled water for $2 \mathrm{hr}$ in a Petri dish. The tissue was then removed from the water and surface-dried using blotting paper, and the turgid weight measured. The same tissue was oven-dried at $110^{\circ} \mathrm{C}$ for $24 \mathrm{hr}$ and then weighed. Stomatal conductance (gs) of leaves was recorded at 11:00 hr with a portable leaf porometer (model SC1; Decagon Devices; Awasthi et al., 2014).

Photosystem II (PS II) function was assessed at 11:00 hr with chlorophyll fluorescence, involving a dark-adapted test with the help of a modulated chlorophyll fluorometer (OS1-FL; OptiSciences). The instrument's clamps were placed on the topmost leaves for $45 \mathrm{~min}$ to maintain a dark environment and to stop the light reaction of photosynthesis. Thereafter, the clamps were fixed to the optic fibre of the instrument before opening the valves. The instrument was switched on, and modulated light (695 nm) was released through the optic fibre to the leaves. PS II was recorded as $F_{\mathrm{v}} / F_{\mathrm{m}}$ ratio (the maximum quantum yield of PSII photochemistry) (Awasthi et al., 2014).

For the estimation of total chlorophyll, fresh leaves were collected from control and heat-stressed plants and homogenised in $80 \%$ acetone to extract the pigments. The extract was measured for chlorophyll at 645 and $663 \mathrm{~nm}$ using a double-beam spectrophotometer (Arnon, 1949).

\section{2 | Carbon fixation and assimilation}

After 10 days of exposure to heat stress at various temperatures, the leaves from second- or third-top branches of plants were assayed for various enzyme activities. To estimate Rubisco activity, fresh leaves were homogenised in a pre-cooled mortar and pestle in a buffer solution comprising 50 mM 1,3-bis-tris(hydroxymethyl) methylamino)propane ( $\mathrm{pH}=7.0), 10 \mathrm{nM} \mathrm{NaHCO}, 10 \mathrm{mM} \mathrm{MgCl}$, $1 \mathrm{mM}$ EDTA, $0.5 \mathrm{mM}$ ATP, $10 \mathrm{mM}$ DTT, $1 \mathrm{mM}$ phenylmethylsulfonyl fluoride, $1 \mathrm{mM}$ benzamidine, $1.5 \%$ polyvinylpolypyrrolidone and $3 \mathrm{mM}$ 3-methylbut-2-ene-1-thiol, according to the method of Wang, Snyder, Esau, Portis, and Ogren (1992). The leaf extract was centrifuged at $29,068 \mathrm{~g}$ for $40 \mathrm{~min}$. The supernatant was de-salted immediately at $4^{\circ} \mathrm{C}$ by passing it through $4 \mathrm{ml}$ Sephadex G-25 columns (Sigma) pre-equilibrated with buffer solution containing 20 mM HEPES- $\mathrm{NaOH}$ (pH 7.5), $0.25 \mathrm{mM} \mathrm{MgCl}_{2}$, 0.01\% 2-mercaptoethanol, 1 mM EDTA and 0.05\% BSA. The de-salted extract was assayed immediately using the method of Racker (1962). The assay medium contained $1 \mathrm{M}$ Tris buffer (pH 7.8), 0.006 M NADH, 0.1 M reduced glutathione, $0.5 \%$ glyceraldehyde-3-phosphate dehydrogenase, 0.025 M 3-phosphoglycerate kinase, 0.05\% a-glycerophosphate dehydrogenase-triose phosphate isomerase, $0.025 \mathrm{M}$ ribulose 1-5 biphosphate, $0.2 \mathrm{M}$ ATP, $0.5 \mathrm{M} \mathrm{MgCl}_{2}$ and $0.5 \mathrm{M}$ $\mathrm{KHCO}_{3}$. The enzyme extract was added to the assay medium to a final volume of $1 \mathrm{ml}$. The oxidation of NADH was observed at $340 \mathrm{~nm}$ during the conversion of 3-phosphoglycerate to glycerol 3-phosphate using a molar extinction coefficient of $6.22 \mathrm{mM} / \mathrm{cm}$. One unit was taken as the amount that catalysed the cleavage of 
$1 \mathrm{mM}$ RuBP per min. The reaction was monitored for $3 \mathrm{~min}$ at $25^{\circ} \mathrm{C}$ until there was a uniform change in the absorbance. Rubisco activity was expressed as mmol NADH oxidised $\mathrm{g}^{-1} \mathrm{dW} \mathrm{min}^{-1}$ (Awasthi et al., 2014).

Sucrose synthase activity was assayed as follows: the leaf samples were homogenised in ice-cold $200 \mathrm{mM} \mathrm{HEPES} / \mathrm{KOH}$ buffer $(\mathrm{pH}$ 7.8) containing $1 \%(w / v)$ polyvinylpyrrolidone (PVP), $10 \mathrm{mM}$ dithiothreitol (DTT), $3 \mathrm{mM}$ magnesium acetate and $3 \mathrm{mM}$ EDTA $\mathrm{Na}_{2} \cdot 2 \mathrm{H}_{2} \mathrm{O}$, followed by centrifugation $(29,068 \mathrm{~g})$ for $20 \mathrm{~min}$ at $4^{\circ} \mathrm{C}$. The supernatant was de-salted immediately using Sephadex G-25 columns (Sigma), pre-treated with a buffer solution having 20 mM HEPES$\mathrm{NaOH}$ (pH 7.5), 1 mM EDTA, 0.01\% 2-mercaptoethanol, 0.05\% BSA and $0.25 \mathrm{mM} \mathrm{MgCl}_{2}$. For the assay, the de-salted extract was used directly (Racker, 1962). Sucrose synthase activity (Hawker, Walker, $\&$ Ruffner, 1976) was assayed from the de-salted extract immediately. Sucrose concentration was analysed following the enzymatic method of Jones, Outlaw, and Lowry (1977).

\section{3 | Oxidative molecules and antioxidants}

After 10 days of exposure to heat stress at various temperatures, the leaves from second- or third-top branches of plants were assayed for oxidative stress and antioxidants.

\subsection{1 | Malondialdehyde}

Malondialdehyde (MDA) concentration is indicative of lipid peroxidation, which was estimated using the method described by Heath and Packer (1968). MDA was extracted from fresh leaf tissue using $0.1 \%$ trichloroacetic acid (TCA), followed by centrifugation at 29,068 $\mathrm{g}$ for $5 \mathrm{~min}$. A fraction of the supernatant $(0.1 \mathrm{ml})$ was reacted with $0.5 \%$ thiobarbituric acid $(4 \mathrm{ml})$, prepared in 20\% TCA. For heating, the mixture was kept at $95^{\circ} \mathrm{C}$ for $0.5 \mathrm{hr}$, and subsequently cooled in an ice bath, before centrifuging at 29,068 $\mathrm{g}$ for $10 \mathrm{~min}$. The supernatant was used to measure the absorbance at $532 \mathrm{~nm}$. The calculation of MDA concentration was measured using an extinction coefficient of $155 \mathrm{mM}^{-1} \mathrm{~cm}^{-1}$.

\subsection{2 | Hydrogen peroxide}

Hydrogen peroxide $\left(\mathrm{H}_{2} \mathrm{O}_{2}\right)$ concentration was estimated as per the method of Mukherjee and Chaudhari (1983) by homogenising leaf tissue in $5 \mathrm{ml}$ chilled acetone (80\%), followed by filtration through Whatman filter paper. The filtrate was treated with $4 \mathrm{ml}$ titanium reagent and then with $5 \mathrm{ml}$ ammonia solution before centrifugation at 29,068 $\mathrm{g}$; the supernatant was discarded. To dissolve the residue, $1 \mathrm{M} \mathrm{H}_{2} \mathrm{SO}_{4}$ was added, and the absorbance was measured on the resultant solution at $410 \mathrm{~nm}$. The concentration of $\mathrm{H}_{2} \mathrm{O}_{2}$ in samples was measured using a standard curve, prepared with pure $\mathrm{H}_{2} \mathrm{O}_{2}$, and an extinction coefficient of $0.28 \mathrm{mmol}^{-1} \mathrm{~cm}^{-1}$.

\subsection{3 | Enzymatic and non-enzymatic antioxidants}

\section{Superoxide dismutase}

Superoxide dismutase (SOD; E.C. 1.15.1.1) activity was measured in fresh tissues, according to the method of DhindsaPlumb-Dhindsa and Thorpe (1981). The tissue was homogenised in chilled phosphate buffer ( $\mathrm{pH} 7.0 ; 50 \mathrm{mM}$ ) and centrifuged at 29,068 $\mathrm{g}$ for $5 \mathrm{~min}$ at $4^{\circ} \mathrm{C}$. The supernatant was used as an enzyme and protein source. The reaction mixture contained $50 \mathrm{mM}$ phosphate buffer $(\mathrm{pH} 7.8)$, $0.1 \mathrm{ml}$ enzyme extract, $0.1 \mathrm{mM}$ EDTA, $25 \mathrm{mM}$ nitro blue tetrazolium chloride (NBT), $13 \mathrm{mM}$ methionine and $50 \mathrm{mM}$ sodium bicarbonate in a total volume of $3 \mathrm{ml}$. The reaction mixture was treated with $2 \mathrm{mM}$ riboflavin and exposed to a $15 \mathrm{~W}$ fluorescent light for $10 \mathrm{~min}$. Absorbance was read at $560 \mathrm{~nm}$. The SOD activity of the samples was determined by measuring its ability to stop the photochemical reduction of NBT. The amount of enzyme that causes $50 \%$ inhibition of the photochemical reduction of NBT was defined as one unit of SOD activity.

Catalase

Catalase (CAT; E.C. 1.11.1.6) activity was measured as per the method of Teranishi, Tanaka, Osumi, and Fukui (1974) with a few minor modifications. The enzyme extract (as above for SOD) was added to a reaction mixture containing $0.1 \mathrm{ml}$ enzyme extract and $50 \mathrm{mM}$ phosphate buffer ( $\mathrm{pH}$ 7.0); the reaction was initiated by adding $200 \mathrm{mM} \mathrm{H}_{2} \mathrm{O}_{2}$. The decline in absorbance was recorded at $410 \mathrm{~nm}$ for $3 \mathrm{~min}$. The enzyme activity was measured using an extinction coefficient of $40 \mathrm{mM}^{-1} \mathrm{~cm}^{-1}$.

\section{Ascorbate peroxidase}

Ascorbate peroxidase (APX; E.C. 1.11.1.11) activity was assayed by recording the oxidation of ascorbate as a decline in absorbance at $290 \mathrm{~nm}$ (Nakano \& Asada, 1981). The enzyme extract (as above for SOD) was added to a reaction mixture containing $50 \mathrm{mM}$ phosphate buffer ( $\mathrm{pH}$ 7.0), $0.5 \mathrm{mM}$ ascorbic acid (ASC) and $0.1 \mathrm{mM}$ EDTA to a total volume of $3 \mathrm{ml} . \mathrm{H}_{2} \mathrm{O}_{2}$ was added to the reaction mixture, as a substrate, and the absorbance recorded at $290 \mathrm{~nm}$ at 30-s intervals. The enzyme activity was measured using an extinction coefficient of $2.8 \mathrm{mM}^{-1} \mathrm{~cm}^{-1}$

\section{Glutathione reductase}

The activity of glutathione reductase (GR; E.C. 1.6.4.2) was assayed according to the method of Mavis and Stellwagen (1968). The enzyme extract (as above for SOD; $0.2 \mathrm{ml}$ ) was added to a reaction mixture containing $1.5 \mathrm{ml}$ phosphate buffer $(100 \mathrm{mM}$, $\mathrm{pH} 7.6), 0.20 \mathrm{ml}$ BSA, $0.35 \mathrm{ml}$ NADP, glutathione oxidised (GSSG) and deionised water. The decline in absorbance was measured at $340 \mathrm{~nm}$ for $3 \mathrm{~min}$.

\section{Ascorbic acid}

Ascorbic acid (ASC) concentration was determined by homogenising fresh leaf tissue in 6\% TCA before centrifuging at $29.068 \mathrm{~g}$ for $15 \mathrm{~min}$ (Mukherjee \& Chaudhari, 1983). To $4 \mathrm{ml}$ of supernatant, 
$2 \mathrm{ml}$ of $2 \%$ DNPH (2,4, dinitrophenylhydrazine) was added, followed by addition of a single drop of thiourea (10\%). The mixture was boiled in a water bath for $15 \mathrm{~min}$ and allowed to cool to room temperature. After cooling, $5 \mathrm{ml} \mathrm{H}_{2} \mathrm{SO}_{4}$ (pre-cooled) was added, and the absorbance was recorded at $530 \mathrm{~nm}$. ASC concentration was measured from a standard curve plotted with its known concentration.

\section{Glutathione}

Reduced glutathione (GSH) concentration was determined as per the method of Griffith (1980) by homogenising fresh leaf tissue in $2 \mathrm{ml}$ metaphosphoric acid, and centrifuging for $5 \mathrm{~min}$ at 29,068 g. A fraction $(0.9 \mathrm{ml})$ of the supernatant was neutralised by adding $0.6 \mathrm{ml}$ of $10 \%$ sodium citrate. A total volume of $1 \mathrm{ml}$ solution was prepared with $100 \mu$ l supernatant, $100 \mu \mathrm{l}$ distilled water, $700 \mu \mathrm{l}$ NADPH $(0.3 \mathrm{mM})$ and $100 \mu \mathrm{l}$ 5,50-dithio-bis-(2-nitrobenzoic acid) DTNB (6 mM), and allowed to stabilise at $25^{\circ} \mathrm{C}$ for 3-4 min, before adding the enzyme GR. The absorbance was measured at $412 \mathrm{~nm}$. GSH concentration was determined from a standard curve of known concentration.

\subsection{Reproductive function}

The plants of chickpea and lentil were exposed to heat stress at the onset of flowering (as detailed in Materials and Methods). The new flowers, which emerged during heat stress, were collected on the day of anthesis, from the entire plants, which have faced heat stress for 10 days. Pollen grains were gathered from these flowers that opened on the same day and pooled for viability testing (Alexander, 1969). Pollen viability was tested by treating the pollen with $0.5 \%$ acetocarmine/Alexander stain. Viable pollen grains were chosen on the basis of shape and size (spherical or triangular) and the stain concentration absorbed by the pollen (Kaushal et al., 2013). Observations were recorded in at least ten microscopic fields.

To measure pollen load and pollen germination (in vivo), the flowers were collected with fully dehiscent anthers and with pollen grains on the stigma. The number of pollen grains on the stigma surface (pollen load) was scored on a 1-5 scale ( $1=$ low and $5=$ high; Srinivasan, Saxena, \& Johansen, 1999). At the same time, non-germinating and germinating pollen grains on the stigma surface were determined (Kaushal et al., 2013).

For analysis of in vitro pollen germination, pollen grains were collected in three replications from five flowers per genotype and germinated according to the method of Brewbaker and Kwack (1963). The germination medium comprised $10 \%$ sucrose, $990 \mathrm{mM}$ potassium nitrate $(\mathrm{pH}$ 6.5), $1.3 \mathrm{mM}$ calcium nitrate, $1.64 \mathrm{mM}$ boric acid and $812 \mathrm{mM}$ magnesium sulphate. Pollen grains were considered germinated when the size of the pollen tube exceeded the diameter of the pollen grain. Germination (\%) was recorded from at least 100 pollen grains per replicate (Kaushal et al., 2013).

Stigma receptivity was tested using an esterase test, which involves $\alpha$-naphthyl acetate as the substrate along with fast blue B in the azo-coupling reaction (Mattson, Knox, Heslop-Harrison, \& Heslop-Harrison, 1974). Stigmas were collected from the flowers one day prior to flower opening; these were dipped in a solution prepared by dissolving $\alpha$-naphthyl acetate and fast blue B in phosphate buffer. The stigmas remained immersed for $15 \mathrm{~min}$ at $37^{\circ} \mathrm{C}$. During this time, the stigma surface developed a reddish-brown colour, the intensity of which indicated the receptivity and was rated on a 1-5 scale ( 1 = lightest colour showing low receptivity and 5 = deepest colour showing high receptivity) (Kaushal et al., 2013).

To assess ovule viability, the TTC (2,3,5-triphenyl-2 H-tetrazolium chloride) reduction test was used. Fresh ovules were extracted from ovaries one day before anthesis. A drop of TTC solution (0.5\% TTC in $1 \%$ sucrose solution) was placed on the ovules on a clean glass slide, covered with coverslip, and the slide placed in a Petri dish with moist layers of filter paper, which was further covered with black paper and incubated in the dark at $25^{\circ} \mathrm{C}$ in a growth chamber for $15 \mathrm{~min}$. Ovule viability was tested under the microscope based on the intensity of red colour developed due to the conversion of TTC to formazan, particularly in the central region. The intensity of the red colour in the ovules depends on the oxidising ability of the cells and was rated on a scale of 1-5 (1 = lowest colour intensity (lowest viability) and $5=$ highest colour intensity (highest viability) (Kaushal et al., 2013).

\subsection{Yield traits}

For yield trait observations, the plants were examined at maturity. Seed and pod numbers and seed weight (per plant basis) were recorded in control and stressed plants.

\subsection{Statistical analysis}

The experiments were arranged in a randomised block design with replications, and mean values of the data are presented. The data were analysed by ANOVA, and least significant differences (LSD) were calculated $(p<.05)$. To compare differences between mean values, Turkey's post hoc test was applied.

\section{RESULTS}

\section{1 | Phenology}

\subsection{1 | Days to flowering}

Chickpea genotypes showed flowering in 103-106 days, while lentil genotypes showed flowering in 98-99 days (Table 1). The plants were transferred to high temperatures at 108 days after sowing for both the species to maintain uniformity of exposure. 


\subsection{2 | Days to podding}

In chickpea genotypes, the podding was achieved in 125-126 days after sowing (DAS) at $30 / 20^{\circ} \mathrm{C}$, almost at the same time at $35 / 25^{\circ} \mathrm{C}, 109-111$ days at $40 / 30^{\circ} \mathrm{C}$ and $108-110$ days at $42 / 32^{\circ} \mathrm{C}$ (Table 1). On the other hand, in lentil genotypes, the podding occurred in $115-116$ DAS at $30 / 20^{\circ} \mathrm{C}, 112-114$ DAS at $35 / 25^{\circ} \mathrm{C}$ and $104-106$ days at $38 / 28^{\circ} \mathrm{C}$, whereas no podding occurred at higher temperatures.

Flowering-to-podding interval (FPI) (Table 1 ) ranged $20-22$ days in chickpea and 17 days in lentil at $30 / 20^{\circ} \mathrm{C}$. At $35 / 25^{\circ} \mathrm{C}$, this interval decreased to $18-21$ days in chickpea and 14-15 days in lentil. At $38 / 28^{\circ} \mathrm{C}$, the interval between flowering and podding declined to 5-9 days in chickpea and 6-7 days in lentil. At $40 / 30^{\circ} \mathrm{C}$ and $42 / 32^{\circ} \mathrm{C}$, in chickpea, this period was reduced to 5-6 days and 4-5 days, respectively, whereas no podding occurred in lentil at these temperatures.

\subsection{3 | Days to maturity}

The plants growing at $30 / 20^{\circ} \mathrm{C}$ matured in $148-146$ days for chickpea and 131-134 days in lentil (Table 1). With increase in temperatures to $38 / 28^{\circ} \mathrm{C}, 40 / 30^{\circ} \mathrm{C}$ and $42 / 32^{\circ} \mathrm{C}$, the plants matured in 134-135, 116-117 and 104-106 days, respectively, in chickpea. In lentil, the maturity was achieved earlier and the corresponding days were $120,98-99$ and 84-87 days, respectively.

The podding-maturity interval (PMI) (Table 1) in chickpea at $30 / 20^{\circ} \mathrm{C}$ ranged $22-26$ days, which decreased to $19-23$ days at $35 / 25^{\circ} \mathrm{C}, 16-20$ days at $38 / 28^{\circ} \mathrm{C}, 5-6$ days at $40 / 30^{\circ} \mathrm{C}$ and $4-5$ days at $42 / 32^{\circ} \mathrm{C}$. At the same time in lentil, podding-maturity interval was $15-19$ days at $30 / 20^{\circ} \mathrm{C}$, which was 17 days at $35 / 25^{\circ} \mathrm{C}$ and 14-16 days at $38 / 28^{\circ} \mathrm{C}$, while no podding was observed at further temperatures.

\subsection{Stress injury to leaves}

Membrane damage, evaluated as electrolyte leakage (expressed in \% values), was noticed to be significantly higher in lentil than in chickpea, even at $35 / 25^{\circ} \mathrm{C}$; at $38 / 28^{\circ} \mathrm{C}$, it was $22.5 \%-24.3 \%$ in lentil genotypes, compared to $16.3 \%-17.9 \%$ in chickpea genotypes (Figure 1). The membrane damage at $40 / 30^{\circ} \mathrm{C}$ increased to $26.4 \%-28.8 \%$ in lentil genotypes and $20.4 \%-20.7 \%$ in chickpea genotypes, and the corresponding values at $42 / 32^{\circ} \mathrm{C}$ were $29 \%-30 \%$ in lentil and $22 \%$ $23.5 \%$ in chickpea, showing significantly more tissue sensitivity of lentil to heat stress.

Chlorophyll (chl) concentration at control temperature $\left(30 / 20^{\circ} \mathrm{C}\right)$ was 19.7-21.4 units (mg/g dw) in chickpea and 19.8-21.4 mg/g dw in lentil, which did not show much change at $35 / 25^{\circ} \mathrm{C}$ in chickpea, but decreased to 16.7-16.9 units in lentil genotypes (Figure 1). At $38 / 28^{\circ} \mathrm{C}$, chlorophyll concentration decreased to $16.9-17.9$ units in chickpea genotypes and 11.4-12.8 units in lentil genotypes. At temperatures of $40 / 30^{\circ} \mathrm{C}$ and $42 / 32^{\circ} \mathrm{C}$, chlorophyll concentration in chickpea reduced to 13.8-14.9 and 11.9-12.9 units, respectively, while it declined to 7.3-8.7 and 6.9-7.8 units in lentil genotypes, respectively (Figure 1).

Photochemical efficiency (PE) in control plants (at $30 / 20^{\circ} \mathrm{C}$ ) ranged $0.76-0.8$ units $\left(F_{\mathrm{v}} / F_{\mathrm{m}}\right)$; at $35 / 25^{\circ} \mathrm{C}$, it decreased to $0.70-0.71$ units in lentil genotypes, with no significant effect in chickpea genotypes (Figure 1). At $38 / 28^{\circ} \mathrm{C}$, PE declined to $0.69-0.73$ units in chickpea and $0.57-0.59$ units in lentil genotypes. At $42 / 32^{\circ} \mathrm{C}$, PE in lentil genotypes was inhibited to $0.22-0.24$ units $(69 \%-73 \%$ reduction over control) compared to $0.53-0.57$ units in chickpea (30\%-45\% reduction), suggesting more damage to electron transport chain of photosynthesis in the former case.

Stomatal conductance (gs) increased in chickpea genotypes up to $40 / 30^{\circ} \mathrm{C}\left(413.4-435.8 \mathrm{mmol} \mathrm{m}^{-2} \mathrm{~s}^{-1}\right)$, before declining at $42 / 32^{\circ} \mathrm{C}$ (387.6-410.6 units), with some variations among genotypes (Figure 2). In lentil, gs increased (424.3-467.9 units) until $38 / 28^{\circ} \mathrm{C}$ and declined significantly at $40 / 30^{\circ} \mathrm{C}$ and $42 / 32^{\circ} \mathrm{C}(267.8-$ 290.8 units). High-temperature stress $\left(40 / 30^{\circ} \mathrm{C}\right.$ and $\left.42 / 32^{\circ} \mathrm{C}\right)$ had a greater inhibitory effect on gs in lentil than chickpea, indicating less transpirational cooling in lentil.

The relative leaf water content (RLWC) did not significantly change in either crop species at $35 / 25^{\circ} \mathrm{C}$ or $38 / 28^{\circ} \mathrm{C}$ but declined significantly at $40 / 30^{\circ} \mathrm{C}$ and $42 / 32^{\circ} \mathrm{C}$, more so in lentil than chickpea, with minor differences among their respective genotypes (Figure 2), which showed generation of more leaf water deficits in lentil.

\section{3 | Photosynthetic activity as carbon fixation and assimilation}

Ribulose 1,5 bisphosphate carboxylase (Rubisco) activity in control plants (growing at $30 / 20^{\circ} \mathrm{C}$ ) ranged 29.6-31.4 units ( $\mu$ mol NADH oxidised $\mathrm{g}^{-1} \mathrm{dw} \mathrm{min}^{-1}$ ) in chickpea genotypes and 28.5-30.5 units in lentil genotypes. At $35 / 25^{\circ} \mathrm{C}$, the Rubisco activity in chickpea genotypes increased, while in lentil genotypes, it decreased significantly, relative to their respective controls (Figure 3). Similarly, at $38 / 28^{\circ} \mathrm{C}$, Rubisco activity increased in chickpea genotypes to 38.5-39.4 units but decreased to 24.6-26.5 units in lentil genotypes. At higher temperatures, Rubisco activity declined significantly in both species. At $42 / 32^{\circ} \mathrm{C}$, lentil genotypes had much significantly less activity (10.6-12.6 units; 58\%-63\% reduction over control) than chickpea (24.7-27.9 units; $22 \%-30 \%$ reduction over control), relative to their respective controls.

At $35 / 25^{\circ} \mathrm{C}$, sucrose concentration increased slightly in chickpea genotypes, relative to the control, but did not change in lentil genotypes (Figure 3). At higher temperatures, the sucrose concentration significantly declined in both species, more so in lentil, than in chickpea. At $40 / 30^{\circ} \mathrm{C}$, sucrose reduced to $11.6-13.8$ units ( $\mu$ moles $/ g$ dw) (50.8\%-56.5\% reduction over control) in lentil and $17.4-19.8$ units (25.2\%-46.2\% reduction over control) in chickpea; and at $42 / 32^{\circ} \mathrm{C}$, these values decreased to $7.9-8.6$ units $(69.3 \%-70.4 \%$ reduction 
(a)
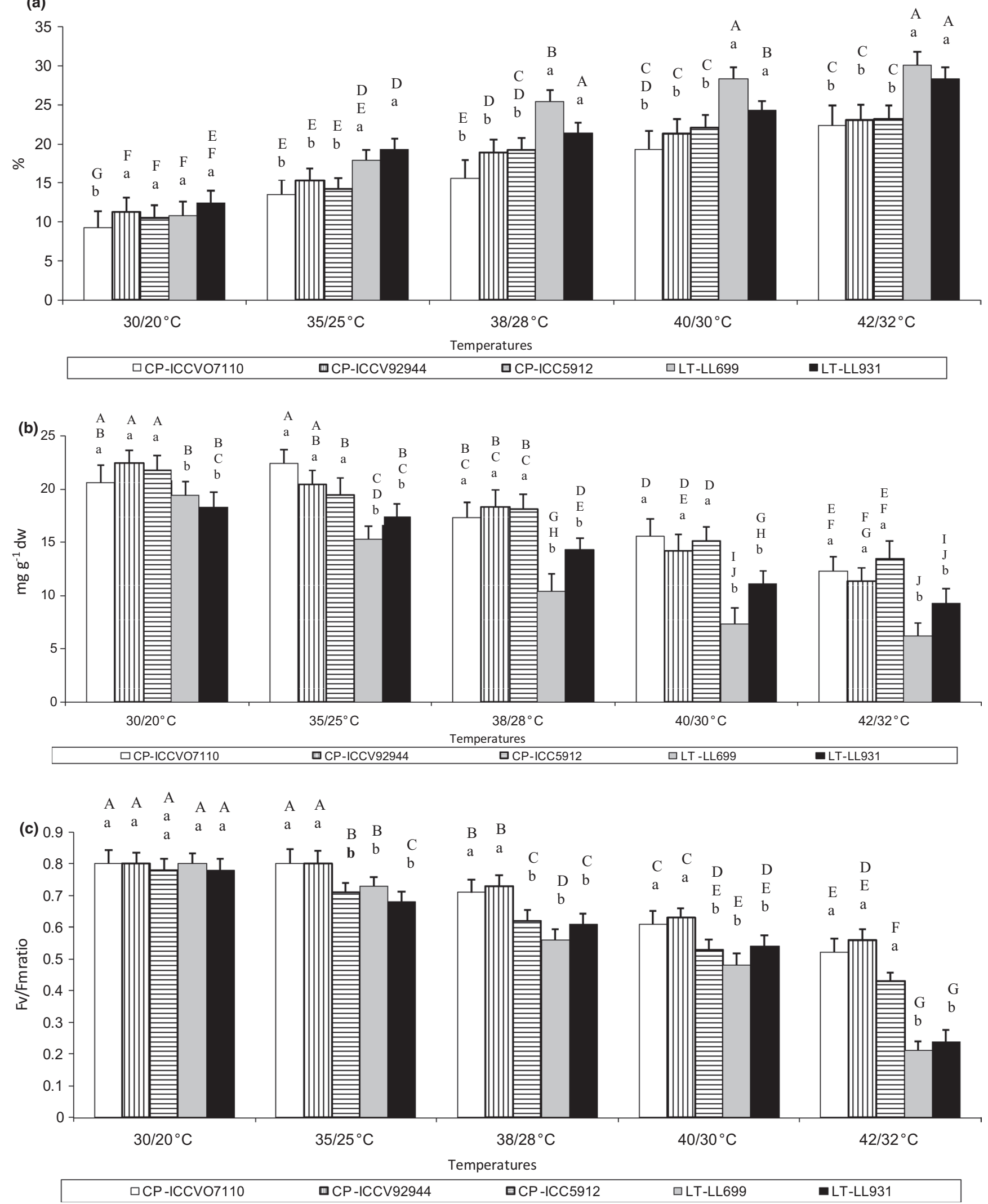

FIGURE 1 Membrane damage (a), chlorophyll concentration (b) and photosystem II function (c) in chickpea (CP) and lentil (LT) genotypes subjected to varying degrees of heat stress at flowering. Small vertical bars represent standard errors. Different capital letters indicate significant differences $(p<.05)$ among genotypes of two species (as per nested ANOVA) across all the temperature treatments. Different small letters on bars indicate significant differences $(p<.05)$ between two species for a particular temperature. Measurements were recorded after 10 days of exposure to heat stress 


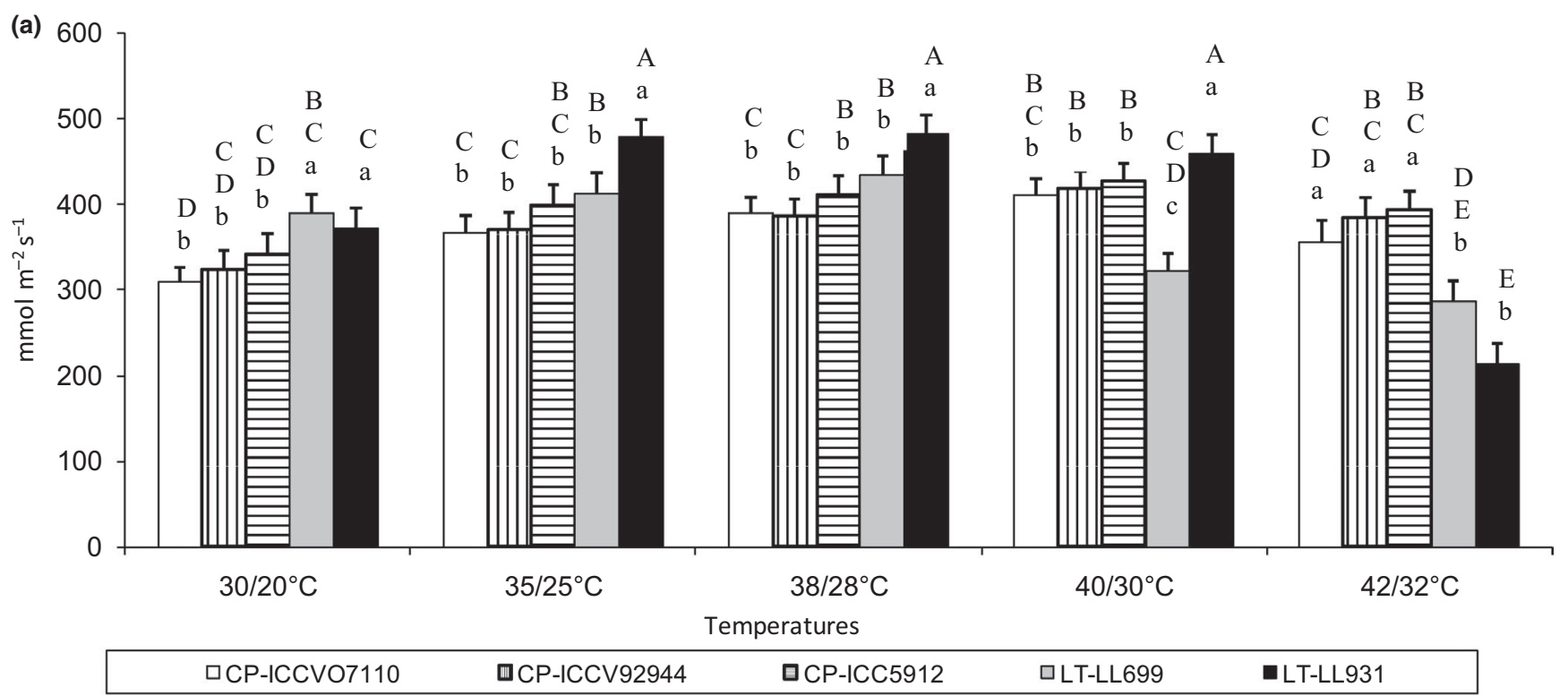

(b)

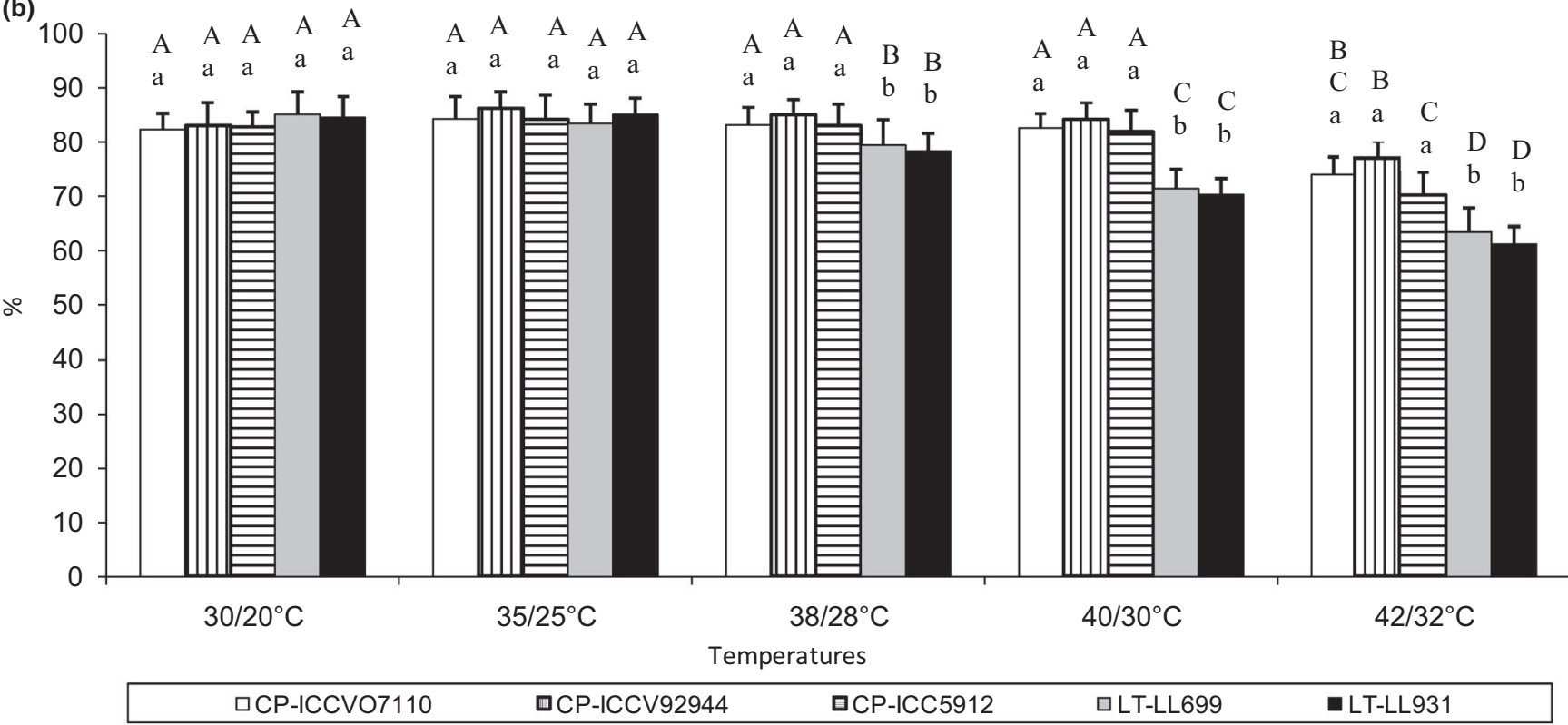

FIGURE 2 Stomatal conductance (a) and relative leaf water content (b) in chickpea (CP) and lentil (LT) genotypes subjected to varying degrees of heat stress at flowering. Small vertical bars represent standard errors. Different small letters on bars indicate significant differences in a trait $(p<.05)$. Different capital letters indicate significant differences $(p<.05)$ among genotypes of two species (as per nested ANOVA) across all the temperature treatments. Different small letters on bars indicate significant differences $(p<.05)$ between two species for a particular temperature. Measurements were recorded after 10 days of exposure to heat stress

over control) in lentil and $10.8-13.5$ units $(46.2 \%-61.9 \%$ reduction over control) in chickpea.

Sucrose synthase (SS) activity ranged 14.9-16.5 units ( $\mu$ mol suc produced $\mathrm{g}^{-1} \mathrm{dw} \mathrm{hr}^{-1}$ ) in chickpea and 15.3-16.8 units in lentil genotypes in leaves of control plants $\left(30 / 20^{\circ} \mathrm{C}\right)$. The enzyme activity increased at $35 / 25^{\circ} \mathrm{C}$, in chickpea genotypes, but did not change significantly in lentil genotypes, compared to their respective controls (Figure 3 ). At $38 / 28^{\circ} \mathrm{C}$, SS activity showed not much change in chickpea genotypes but decreased to 10.7-11.3 units in lentil genotypes. At $40 / 30^{\circ} \mathrm{C}$, SS activity was significantly inhibited in both species, relative to their respective controls, more so in lentil (47\%-48\% reduction) than chickpea (20\%-37\%). At $42 / 32^{\circ} \mathrm{C}$, SS activity declined further in both species, considerably more in lentil (71\%-73\% over control) than chickpea (39.1\%-50\% over control) genotypes. These observations indicated more inhibition in carbon fixation and assimilation in lentil at all the stressful temperatures. 
(a)

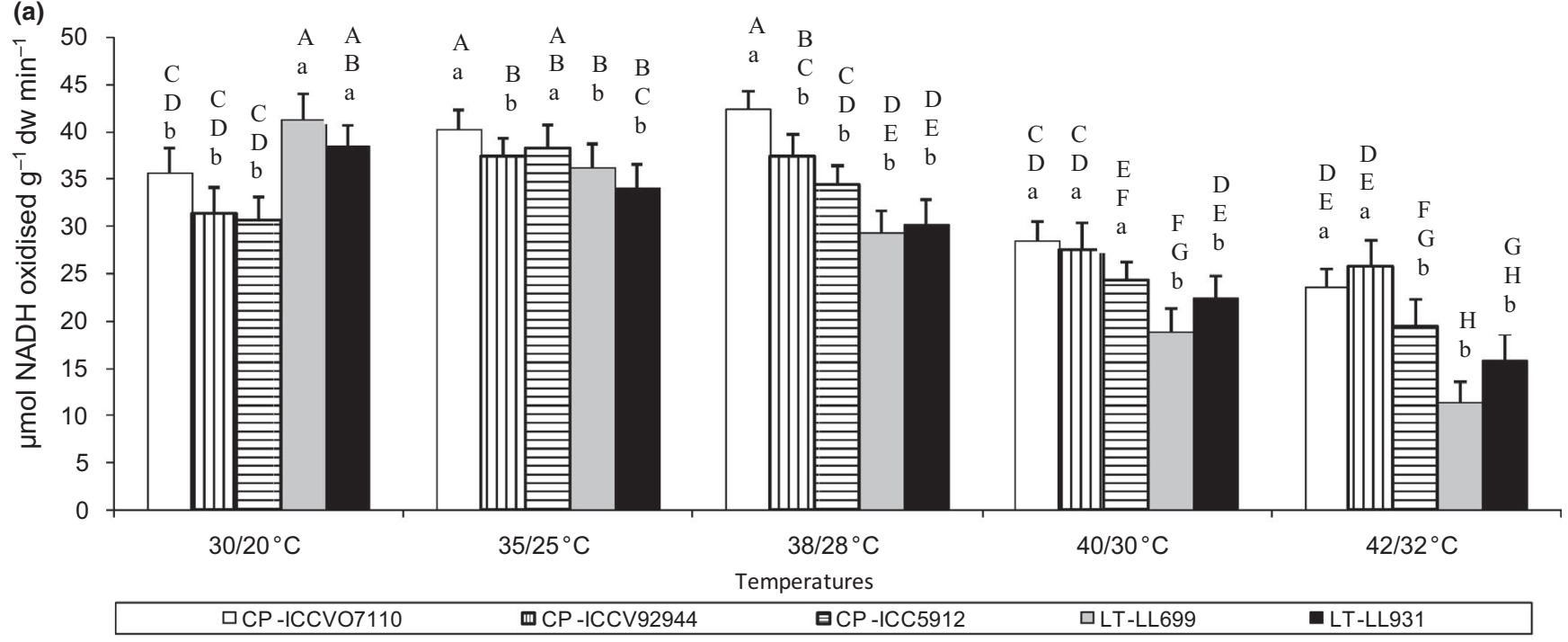

(b)

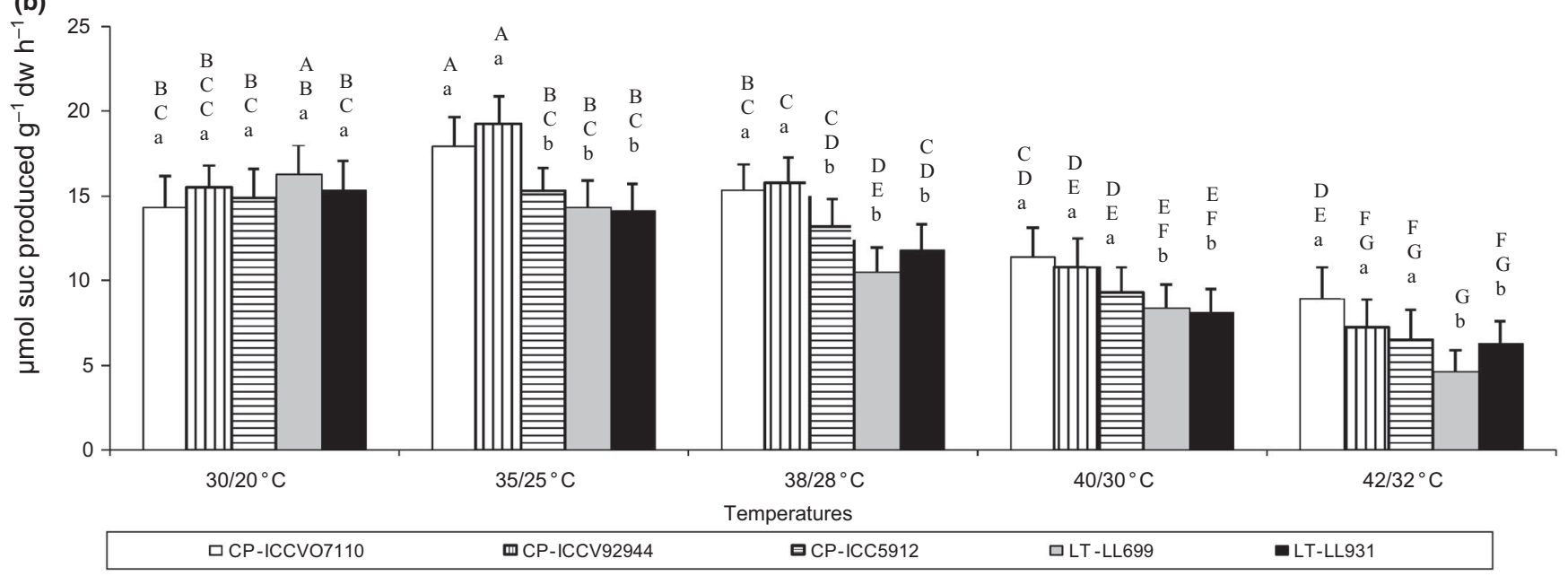

(c)

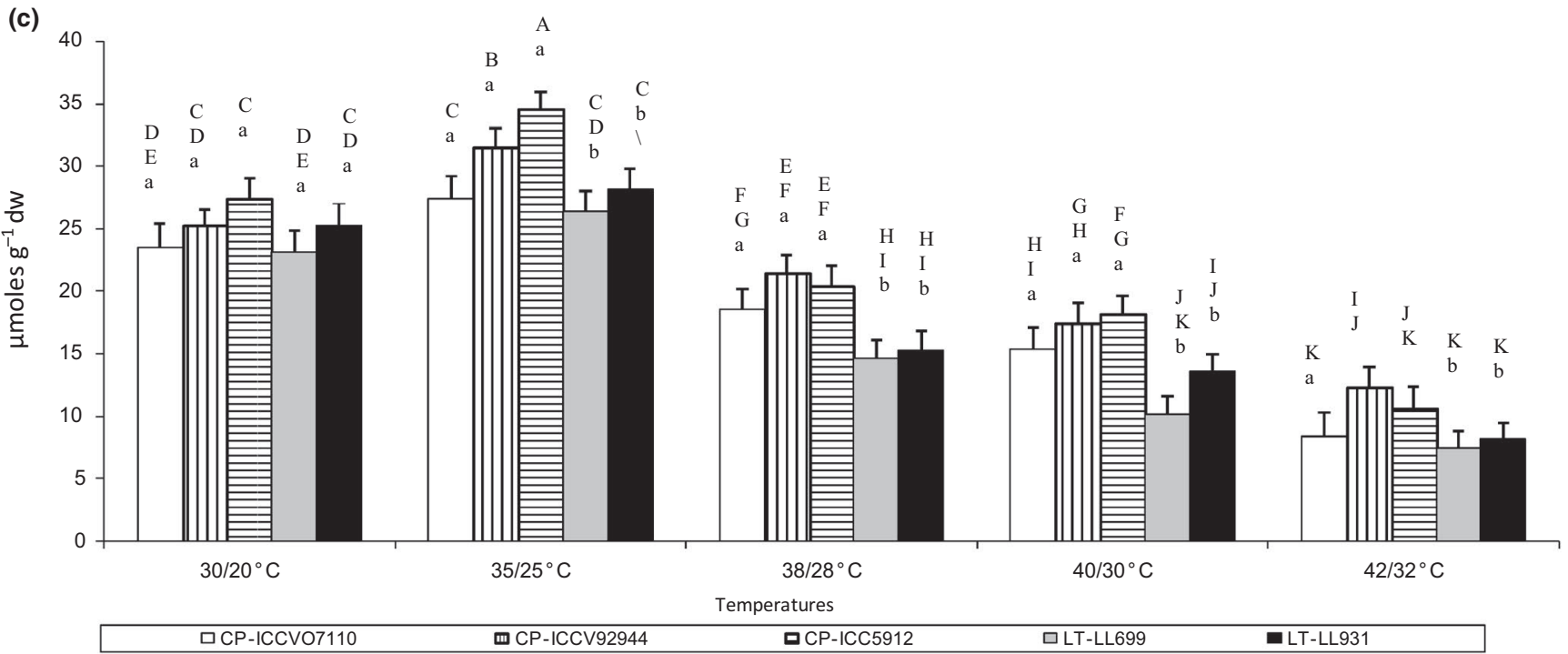

FIGURE 3 Ribulose 1,5 bisphosphate carboxylase activity (a), sucrose synthase (b) and sucrose concentration (c) in chickpea (CP) and lentil (LT) genotypes subjected to varying degrees of heat stress at flowering. Small vertical bars represent standard errors. Different capital letters indicate significant differences $(p<.05)$ among genotypes of two species (as per nested ANOVA) across all the temperature treatments. Different small letters on bars indicate significant differences $(p<.05)$ between two species for a particular temperature. Measurements were recorded after 10 days of exposure to heat stress 


\section{4 | Oxidative damage and antioxidants}

\subsection{1 | Oxidative molecules}

Oxidative damage was assessed using the concentrations of malondialdehyde (MDA) and hydrogen peroxide $\left(\mathrm{H}_{2} \mathrm{O}_{2}\right)$ (Figure 4). MDA concentration ranged between 8.1 and 9.3 nmoles/g dw and 7.98.9 units in controls of chickpea and lentil genotypes, respectively.
At $38 / 28^{\circ} \mathrm{C}, 40 / 30^{\circ} \mathrm{C}$ and $42 / 32^{\circ} \mathrm{C}$, MDA increased to $26.3-24.7$, 28.9-32.3 and 38.7-41.3 units in lentil, while the increase was considerably less in chickpea (12.9-14.7, 18.3-20.9 and 23.4-24.3 units, respectively).

$\mathrm{H}_{2} \mathrm{O}_{2}$ concentration in controls of chickpea and lentil was 1.341.63 and $1.45-1.62 \mathrm{nmoles} / \mathrm{g} \mathrm{dw}$, which increased to 4.9-5.1 units (3.16- to 3.37 -fold) at $40 / 30^{\circ} \mathrm{C}$ in lentil and $2.78-3.15$ units (1.95- to 2.0-fold) in chickpea. At $42 / 32^{\circ} \mathrm{C}$, it increased further to $9.12-10.4$

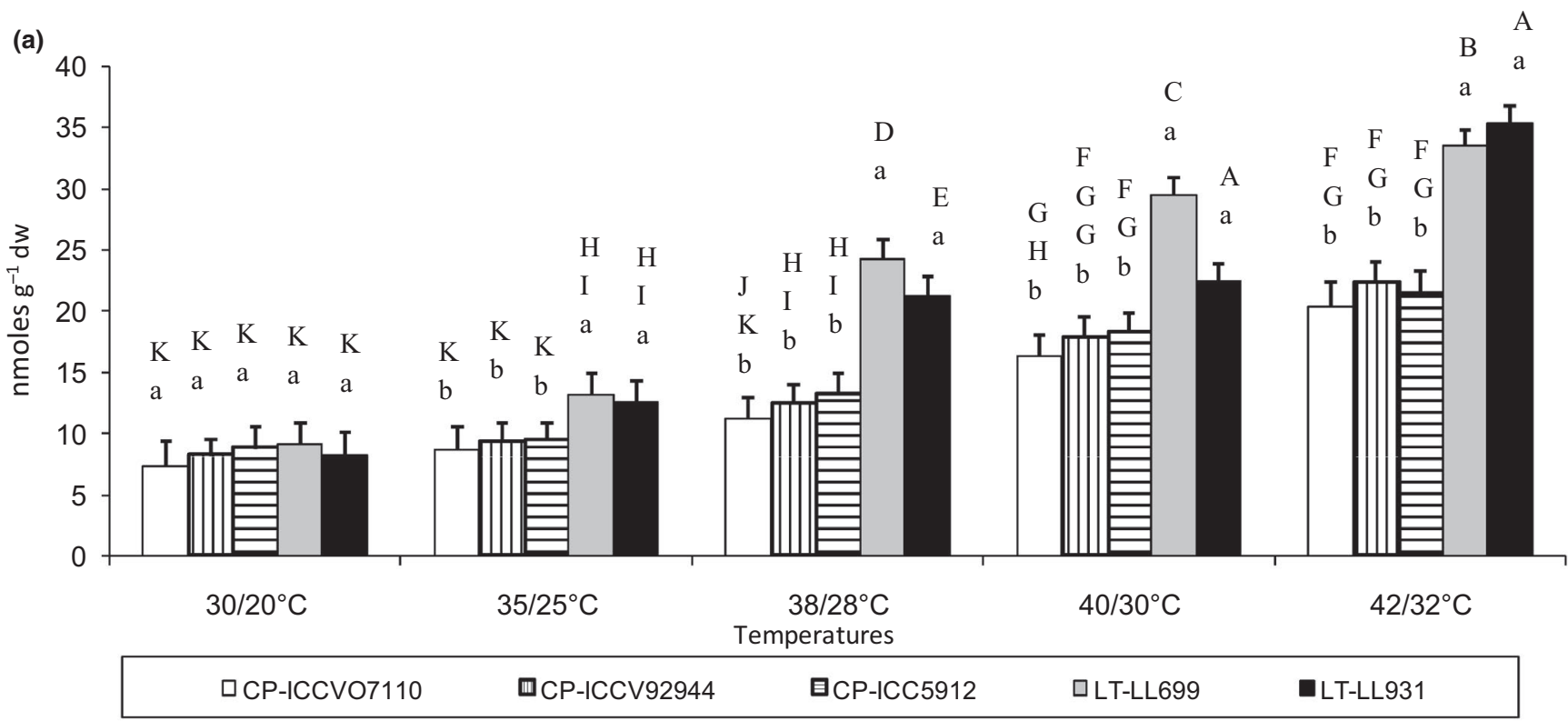

(1)

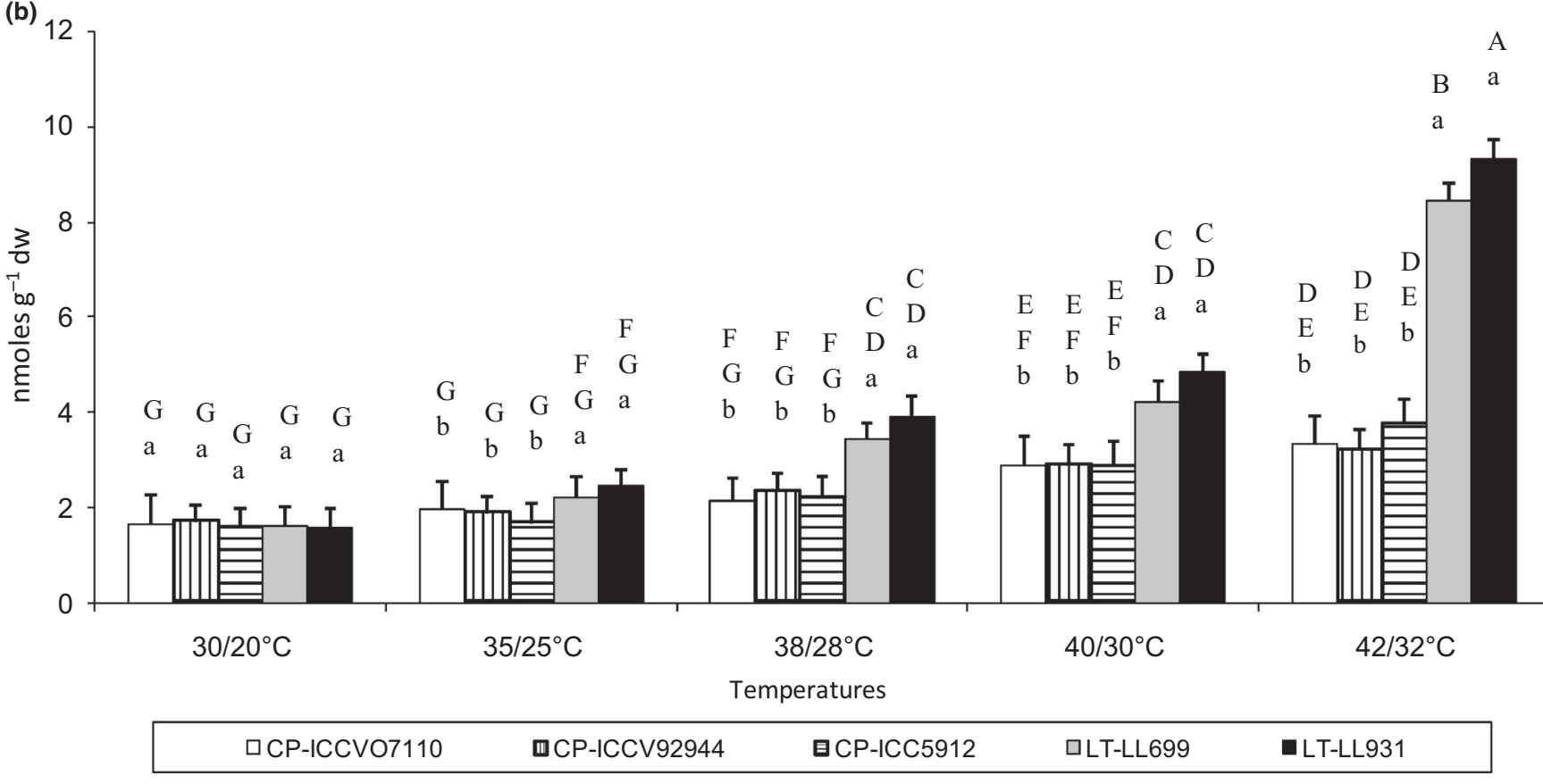

FIGURE 4 Malondialdehyde (a) and hydrogen peroxide (b) concentration in chickpea (CP) and lentil (LT) genotypes subjected to varying degrees of heat stress at flowering. Small vertical bars represent standard errors. Different capital letters indicate significant differences $(p<.05)$ among genotypes of two species (as per nested ANOVA) across all the temperature treatments. Different small letters on bars indicate significant differences $(p<.05)$ between two species for a particular temperature. Measurements were recorded after 10 days of exposure to heat stress 
units (6.28- to 6.41-fold over control) in lentil and 2.98-3.86 units (2.98- to 3.86-fold over control) in chickpea, clearly indicating more oxidative damage to lentil genotypes.

\subsection{2 | Enzymatic antioxidants}

Superoxide dismutase (SOD) activity increased with increasing temperature in both species up to $38 / 28^{\circ} \mathrm{C}$, more so in lentil genotypes
(Figure 5). At $40 / 30^{\circ} \mathrm{C}$ and $42 / 32^{\circ} \mathrm{C}$, chickpea genotypes had greater SOD activity than lentil genotypes. Compared to SOD activity in control of chickpea (1.89-1.96 units/mg protein) and lentil (1.84-1.89 units), at $42 / 32^{\circ} \mathrm{C}$, SOD activity in chickpea genotypes increased to $3.46-3.67$ units (78\%-90\% increase over control), while it declined to $0.78-0.88$ units $(52 \%-58 \%$ reduction over control) in lentil genotypes.

Similarly, catalase (CAT) activity increased with increasing temperature in both species up to $38 / 28^{\circ} \mathrm{C}$, more so in lentil genotypes (a)

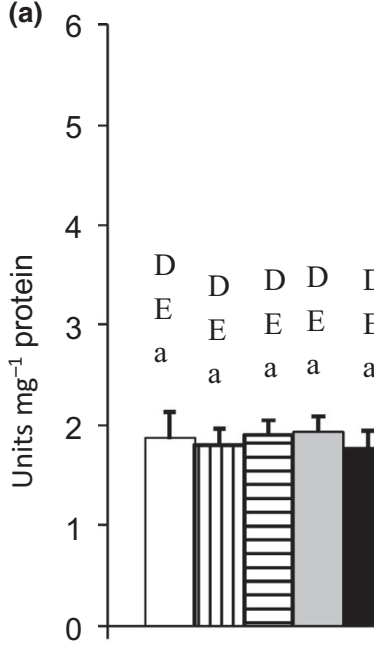

$30 / 20^{\circ} \mathrm{C}$

$35 / 25^{\circ} \mathrm{C}$

$38 / 28^{\circ} \mathrm{C}$

A A

a $\mathrm{a}$

B B

a $\mathrm{a}$

C

B B

a

$\mathrm{C}$

T $\mathrm{T} b$

D D D

a

$\mathrm{D} r \mathrm{D}$

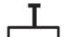

每

eratures

Temperatures

口CP-ICCVO7110

ШCP-ICCV92944

日CP-ICC5912

पLT-LL699

- LT-LL931

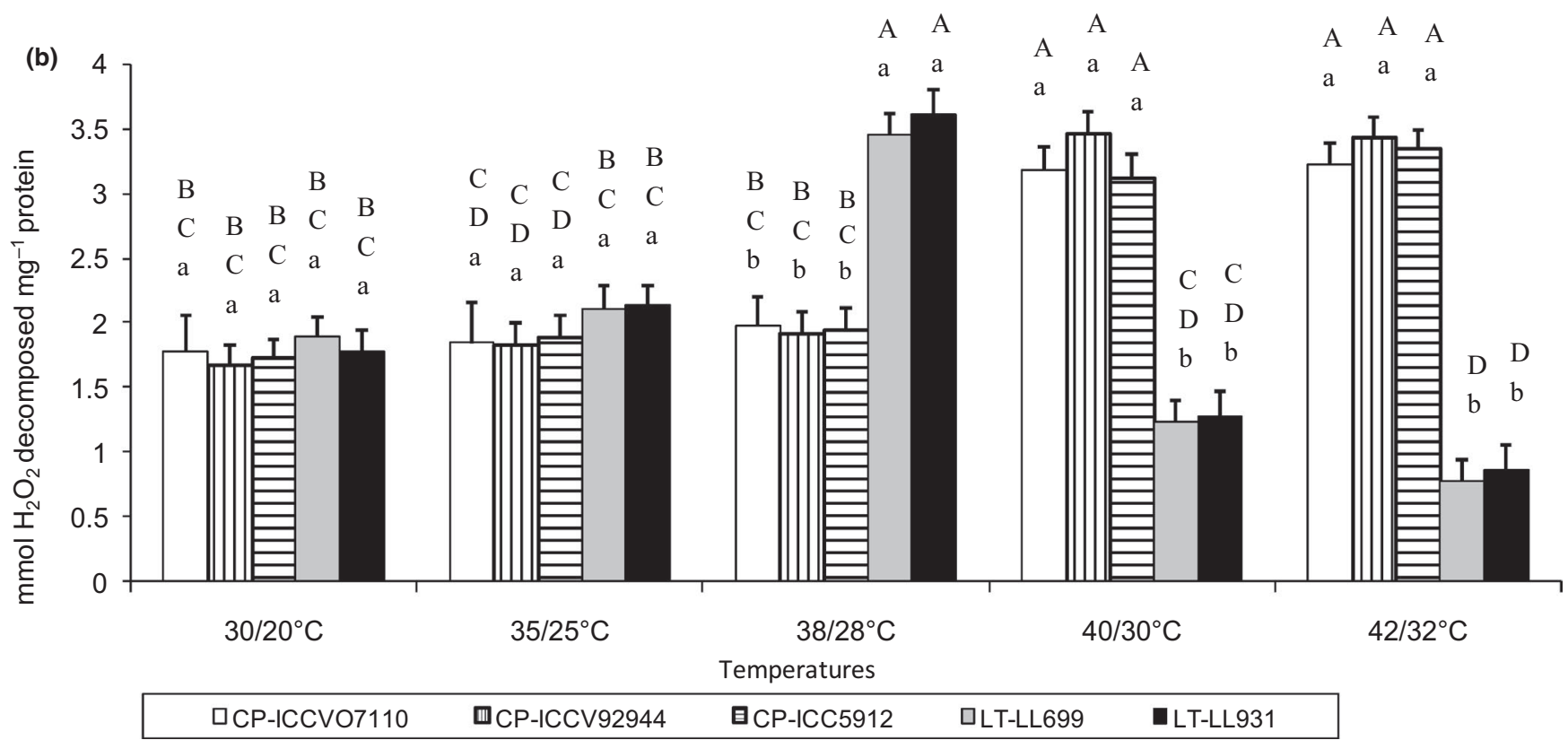

FIGURE 5 Superoxide dismutase (a) and catalase (b) activities in chickpea (CP) and lentil (LT) genotypes subjected to varying degrees of heat stress at flowering. Small vertical bars represent standard errors. Different capital letters indicate significant differences $(p<.05)$ among genotypes of two species (as per nested ANOVA) across all the temperature treatments. Different small letters on bars indicate significant differences $(p<.05)$ between two species for a particular temperature. Measurements were recorded after 10 days of exposure to heat stress 
(Figure 5). At higher temperatures, CAT activity increased further in chickpea genotypes, relative to the control, but decreased in lentil genotypes. At $42 / 32^{\circ} \mathrm{C}$, in chickpea genotypes, CAT activity increased to 3.67-3.87 ( $\mathrm{mmol} \mathrm{H}_{2} \mathrm{O}_{2}$ decomposed/mg protein) (95\%-111\% higher than its control), while the activity declined in lentil genotypes to $0.82-0.89$ units $(51 \%-57 \%$ reduction over control).

Ascorbate peroxidase (APX) activity in control plants ranged between 0.78 and $0.91 \mathrm{mmol} \mathrm{H}_{2} \mathrm{O}_{2}$ decomposed/mg protein, which increased to $1.23-1.35$ units lentil genotypes at $35 / 25^{\circ} \mathrm{C}$ and 0.89 0.97 units in chickpea genotypes (Figure 6). At $38 / 28^{\circ} \mathrm{C}$, lentil genotypes had considerably higher APX activity (2.78-2.91 units) than chickpea genotypes (1.38-1.51 units), but the trend was reversed at subsequent higher temperatures. Thus, at $42 / 32^{\circ} \mathrm{C}$, chickpea genotypes had $2.34-2.54$ units of APX activity (181\%-225\% increase over control) while lentil genotypes showed $0.59-0.71$ units $(22 \%-$ $29 \%$ reduction over control).

Glutathione reductase (GR) activity, at $38 / 28^{\circ} \mathrm{C}$, was significantly more in lentil genotypes (3.87-3.98 mmol $\mathrm{H}_{2} \mathrm{O}_{2}$ oxidised donor decomposed/mg protein) than chickpea genotypes (2.452.67 units); on the other hand, at higher temperatures, GR activity in lentil declined markedly, to below the control, at $42 / 32^{\circ} \mathrm{C}$, compared to increased activity in chickpea genotypes (Figure 6). At $42 / 32^{\circ} \mathrm{C}$ too, chickpea genotypes had significantly higher GR activity (4.184.99 units), while it was significantly lower (0.87-0.91 units) in lentil genotypes.
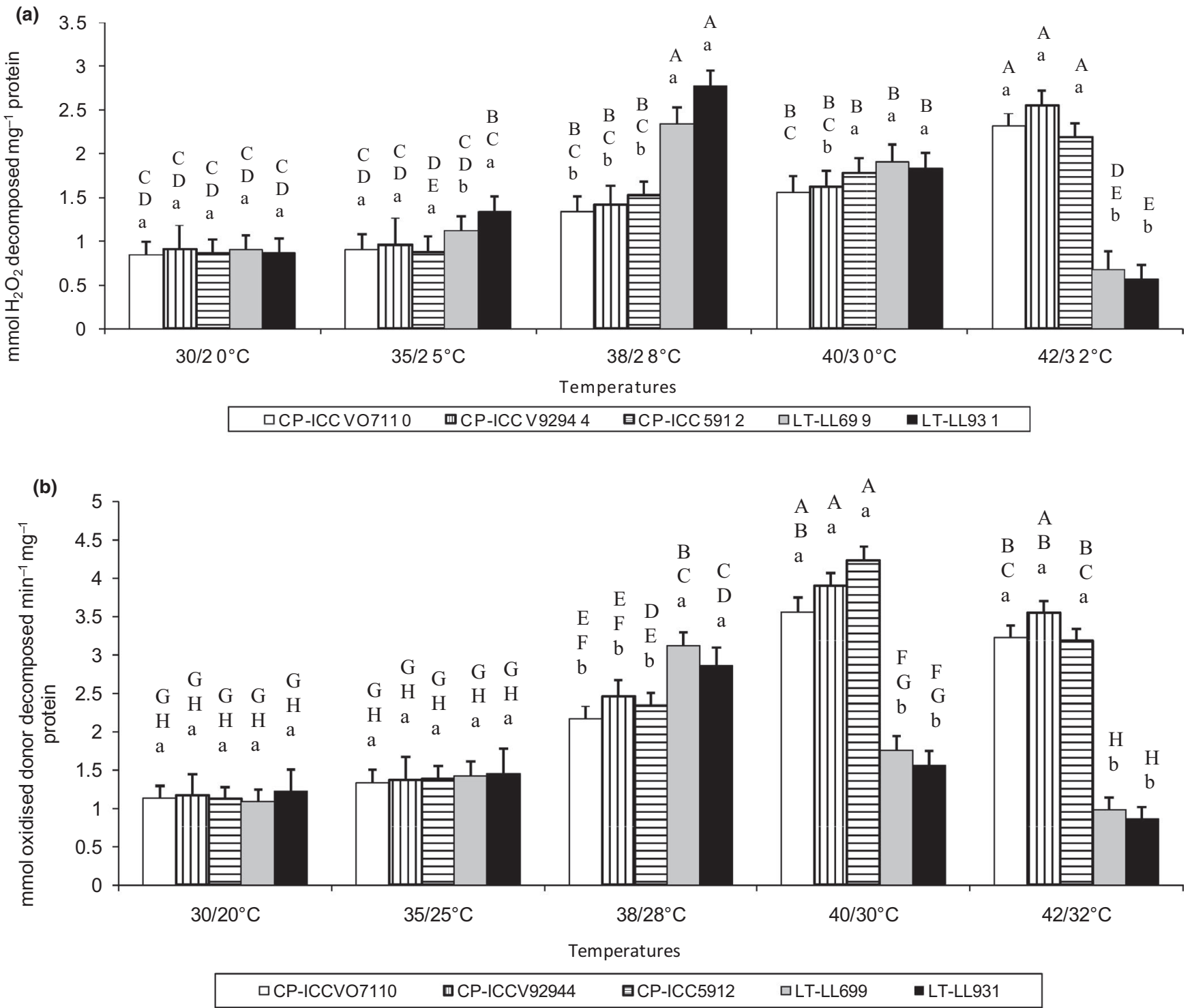

FIGURE 6 Ascorbate peroxidase (a) and glutathione reductase (b) activities in chickpea (CP) and lentil (LT) genotypes subjected to varying degrees of heat stress at flowering. Small vertical bars represent standard errors. Different capital letters indicate significant differences $(p<.05)$ among genotypes of two species (as per nested ANOVA) across all the temperature treatments. Different small letters on bars indicate significant differences $(p<.05)$ between two species for a particular temperature. Measurements were recorded after 10 days of exposure to heat stress 


\subsection{3 | Non-enzymatic antioxidants}

Ascorbic acid (ASC) concentration increased with increasing temperature in chickpea genotypes, but not in lentil genotypes, which decreased considerably at $40 / 30^{\circ} \mathrm{C}$ and $42 / 32^{\circ} \mathrm{C}$ (Figure 7). At $42 / 32^{\circ} \mathrm{C}$, ASC concentration in lentil genotypes declined below the control value and was about 3.4-fold higher in chickpea genotypes (65.8-68.4 nmoles/g dw) than lentil genotypes (19.9-22.3 units).

The reduced glutathione (GSH) concentration increased more in lentil genotypes than chickpea genotypes at $35 / 25^{\circ} \mathrm{C}$ and $38 / 28^{\circ} \mathrm{C}$, relative to their respective controls (Figure 7). On the other hand, at higher temperature $\left(42 / 32^{\circ} \mathrm{C}\right), \mathrm{GSH}$ concentration was 2.4 - to 3.0fold more in chickpea genotypes (37.9-42.1 nmoles/g dw), compared to lentil genotypes having 14.3-17.8 units.

\section{5 | Reproductive function}

The chickpea and lentil controls $\left(30 / 20^{\circ} \mathrm{C}\right)$ had $83.5 \%-86.9 \%$ and $85.3 \%-88.1 \%$ viable pollen, respectively (Table 2). An increase
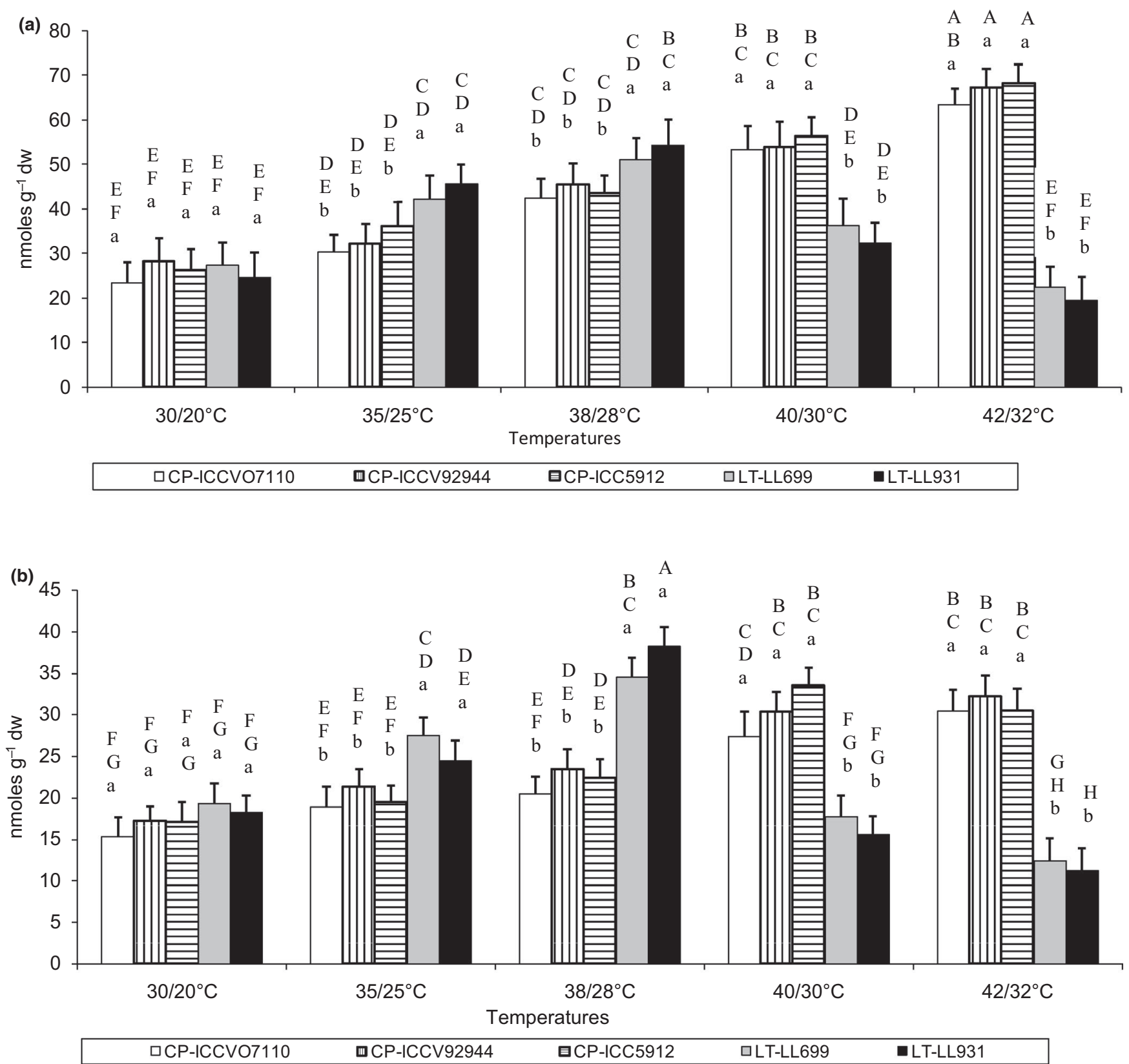

FIGURE 7 Ascorbate (a) and reduced glutathione (b) concentration in chickpea (CP) and lentil (LT) genotypes subjected to varying degrees of heat stress at flowering. Small vertical bars represent standard errors. Different capital letters indicate significant differences $(p<.05)$ among genotypes of two species (as per nested ANOVA) across all the temperature treatments. Different small letters on bars indicate significant differences $(p<.05)$ between two species for a particular temperature. Measurements were recorded after 10 days of exposure to heat stress 
TAB LE 2 Reproductive function of chickpea (CP) and lentil (LT) genotypes at different high temperatures

\begin{tabular}{|c|c|c|c|c|c|}
\hline & $30 / 20^{\circ} \mathrm{C}$ & $35 / 25^{\circ} \mathrm{C}$ & $38 / 28^{\circ} \mathrm{C}$ & $40 / 30^{\circ} \mathrm{C}$ & $42 / 32^{\circ} \mathrm{C}$ \\
\hline CP-ICCV07110 & $83.5 \pm 2.4 \mathrm{Aa}$ & $87.3 \pm 2.5 \mathrm{Aa}$ & $79.3 \pm 2.4 \mathrm{Ba}$ & $61.3 \pm 2.4 \mathrm{Da}$ & $37.5 \pm 2.6 \mathrm{Ea}$ \\
\hline CP-ICVV92944 & $86.9 \pm 2.4 \mathrm{Aa}$ & $84.3 \pm 2.4$ Aaа & $72.5 \pm 2.6 \mathrm{Ba}$ & $63.4 \pm 2.5 \mathrm{Da}$ & $33.9 \pm 2.4 \mathrm{Ea}$ \\
\hline CP-ICC5912 & $84.3 \pm 2.6 \mathrm{Aa}$ & $82.5 \pm 2.5 \mathrm{ABa}$ & $78.3 \pm 2.5 \mathrm{Ba}$ & $57.5 \pm 2.4 \mathrm{dea}$ & $36.7 \pm 2.5 \mathrm{Ea}$ \\
\hline LT-LL699 & $88.1 \pm 2.5 \mathrm{Aa}$ & $68.4 \pm 2.5 \mathrm{Cb}$ & $55.3 \pm 2.6 \mathrm{Cb}$ & $18.0 \pm 2.6 \mathrm{fb}$ & 0 \\
\hline \multicolumn{6}{|c|}{ Pollen germination (\%) } \\
\hline CP-ICCV07110 & $84.7 \pm 4.1 \mathrm{Aa}$ & $76.5 \pm 3.2 \mathrm{Ba}$ & $64.5 \pm 4.2 \mathrm{Da}$ & $58.4 \pm 4.2 \mathrm{DEa}$ & $29.5 \pm 2.4 \mathrm{Ga}$ \\
\hline CP-ICVV92944 & $81.6 \pm 4.2 \mathrm{Aa}$ & $78.4 \pm 4.1 \mathrm{Ba}$ & $63.2 \pm 5.5 \mathrm{Da}$ & $60.4 \pm 5.3 \mathrm{Da}$ & $24.6 \pm 1.9 \mathrm{Ga}$ \\
\hline CP-ICC5912 & $80.5 \pm 3.2 \mathrm{Aa}$ & $713 \pm 4.3 \mathrm{Ca}$ & $62.4 \pm 6.1 \mathrm{Da}$ & $61.6 \pm 4.4 \mathrm{Da}$ & $28.2 \pm 2.6 \mathrm{Ga}$ \\
\hline CP-ICCV07110 & $24.6 \pm 1.31 \mathrm{Ba}$ & $20.4 \pm 1.28 \mathrm{BCa}$ & $16.8 \pm 1.5 \mathrm{Ca}$ & $9.4 \pm 0.58 \mathrm{Ca}$ & $4.2 \pm 0.32 \mathrm{DEa}$ \\
\hline CP-ICVV92944 & $27.9 \pm 1.35 \mathrm{Aa}$ & $19.5 \pm 1.27 \mathrm{BCa}$ & $15.8 \pm 1.7 \mathrm{Ca}$ & $8.3 \pm 0.65 \mathrm{Ca}$ & $4.6 \pm 0.44 \mathrm{DEa}$ \\
\hline CP-ICC5912 & $21.5 \pm 1.31 \mathrm{BCa}$ & $18.7 \pm 1.23 \mathrm{BCa}$ & $16.9 \pm 1.4 \mathrm{Ca}$ & $9.1 \pm 0.56 \mathrm{Ca}$ & $3.8 \pm 0.42 \mathrm{Ea}$ \\
\hline LT-LL699 & $28.9 \pm 1.46 \mathrm{Ba}$ & $16.9 \pm 1.24 \mathrm{Cb}$ & $7.2 \pm 1.6 \mathrm{Db}$ & $1.3 \pm 0.65 \mathrm{~Eb}$ & 0 \\
\hline LT-LL931 & $31.4 \pm 1.42 \mathrm{Ba}$ & $18.7 \pm 1.21 \mathrm{BCb}$ & $5.9 \pm 1.6 \mathrm{Db}$ & $1.7 \pm 0.42 \mathrm{eb}$ & 0 \\
\hline \multicolumn{6}{|c|}{ Stigma receptivity (1-5 scale) } \\
\hline CP-ICCV07110 & $4.1 \pm 0.45 \mathrm{Aa}$ & $3.8 \pm 0.42 \mathrm{Ba}$ & $3.1 \pm 0.31 \mathrm{Ba}$ & $2.9 \pm 0.32 \mathrm{Ca}$ & $2.1 \pm 0.11 \mathrm{Ca}$ \\
\hline CP-ICVV92944 & $4.3 \pm 0.34 \mathrm{Aa}$ & $3.6 \pm 0.46 \mathrm{Ba}$ & $3.3 \pm 0.38 \mathrm{Ba}$ & $2.7 \pm 0.27 \mathrm{Ca}$ & $2.4 \pm 0.14 \mathrm{Ca}$ \\
\hline CP-ICC5912 & $4.6 \pm 0.28 \mathrm{Aa}$ & $3.4 \pm 0.35 \mathrm{Ba}$ & $3.4 \pm 0.42 \mathrm{Ba}$ & $2.8 \pm 0.21 \mathrm{Ca}$ & $2.3 \pm 0.16 \mathrm{Ca}$ \\
\hline LT-LL699 & $86.9 \pm 4.8 \mathrm{Aa}$ & $71.5 \pm 3.4 \mathrm{Bb}$ & $43.4 \pm 2.4 \mathrm{~Eb}$ & 0 & 0 \\
\hline LT-LL931 & $86.9 \pm 3.2 \mathrm{Aa}$ & $73.9 \pm 3.4 \mathrm{Bb}$ & $46.2 \pm 2.6 \mathrm{~Eb}$ & 0 & 0 \\
\hline
\end{tabular}

Note: Mean values along with standard errors are presented. Different capital letters indicate significant differences $(p<.05)$ among genotypes of two species (as per nested ANOVA) across all the temperature treatments. Different small letters on bars indicate significant differences ( $p<.05)$ between two species for a particular temperature. Measurements were recorded after 10 days of exposure to heat stress.

in temperature to $35 / 25^{\circ} \mathrm{C}$ had little effect on pollen viability in chickpea but reduced it to $65 \%-68 \%$ in lentil genotypes. At $38 / 28^{\circ} \mathrm{C}$, pollen viability decreased to $72 \%-79 \%$ in chickpea and $55 \%-58 \%$ in lentil genotypes. At $40 / 30^{\circ} \mathrm{C}$, it declined to $57 \%-63.4 \%$ in chickpea and $18 \%-21.4 \%$ in lentil genotypes and genotypes. At $42 / 32^{\circ} \mathrm{C}$, pollen viability showed reduction to $33.9 \%-37.5 \%$ in chickpea, while lentil pollen did not show any viability at this temperature.

In both species, an increase in temperature inhibited pollen germination, more so in lentil genotypes than chickpea genotypes (Table 2). At $30 / 20^{\circ} \mathrm{C}$, pollen germination ranged $80 \%-84 \%$ in chickpea and $82 \%-87 \%$ in lentil genotypes. It decreased to $71 \%-78 \%$ in chickpea and $63 \%-67 \%$ in lentil at $35 / 25^{\circ} \mathrm{C}$. As the temperature was increased to $40 / 30^{\circ} \mathrm{C}$ and $42 / 32^{\circ} \mathrm{C}$, germination decreased to
$58 \%-61 \%$ and $24 \%-29 \%$, respectively, in chickpea genotypes, while in lentil, it declined substantially to $11 \%-12.5 \%$ at $40 / 30^{\circ} \mathrm{C}$, and there was no germination at $42 / 32^{\circ} \mathrm{C}$.

At $35 / 25^{\circ} \mathrm{C}$, the pollen tube growth was inhibited more in lentil genotypes than in chickpea genotypes, relative to their respective controls (Table 2). At $38 / 28^{\circ} \mathrm{C}$, pollen tube growth declined to $15.8-$ $16.9 \mu \mathrm{m}(21-43 \%$ reduction over control) in chickpea and 5.9-7.2 units (75\%-80\% reduction over control in lentil genotypes. A similar trend was evident at higher temperatures. At $40 / 30^{\circ} \mathrm{C}$, the tube growth showed $62 \%-64 \%$ reduction over control in chickpea, while it was $85 \%-90 \%$ in lentil genotypes. At $42 / 32^{\circ} \mathrm{C}$, chickpea genotypes showed markedly marked reduction in pollen tube growth (3.8-4.6 units; $81 \%-88 \%$ reduction over control), while lentil genotypes did not show any growth at this temperature. 
At $35 / 25^{\circ} \mathrm{C}$, stigma receptivity in lentil genotypes was significantly less (2.7-2.8 units (1-5 scale) than chickpea genotypes (3.43.8 units) (Table 2). At $42 / 32^{\circ} \mathrm{C}$, stigma receptivity was severely inhibited in both species. Chickpea showed stigma receptivity of 2.1-2.4 units; $44 \%-50 \%$ reduction over control), while lentil genotypes were completely inhibited.

Pod set declined more in lentil than chickpea genotypes, in all the stress treatments (Table 2). At $38 / 28^{\circ} \mathrm{C}, 40 / 30^{\circ} \mathrm{C}$ and $42 / 32^{\circ} \mathrm{C}$, the pod set was $62.8 \%-65.6 \%, 51 \%-54 \%$ and $24 \%-27 \%$ in chickpea genotypes. At the same time, in lentil, the pod set was $43.4 \%-46.2 \%$ at $38 / 28^{\circ} \mathrm{C}$, while no pods were produced at $40 / 30^{\circ} \mathrm{C}$ and $42 / 32^{\circ} \mathrm{C}$.

\subsection{Growth and yield traits}

\subsection{1 | Biomass}

Compared to the control $\left(30 / 20^{\circ} \mathrm{C}\right)$, the aboveground biomass increased significantly at $35 / 25^{\circ} \mathrm{C}$ in chickpea genotypes but decreased significantly in lentil genotypes (Table 3). At $38 / 28^{\circ} \mathrm{C}$, biomass declined to $5.29-5.50 \mathrm{~g} /$ plant (11\%-25\% reduction over control) in chickpea genotypes, and 3.28-3.82 g/plant (40\%-47\% reduction over control) in lentil genotypes. At $40 / 30^{\circ} \mathrm{C}$, biomass decreased by $18 \%-42 \%$ in chickpea and $69 \%-71 \%$ in lentil genotypes over control. At further higher temperature of $42 / 32^{\circ} \mathrm{C}$, biomass decreased by $48 \%-54 \%$ over control in chickpea and $74 \%-79 \%$ over control in lentil genotypes.

\subsection{2 | Pods/plant}

The controls $\left(30 / 20^{\circ} \mathrm{C}\right)$ of chickpea and lentil showed $18.9-21.3$ and 63.5-68.8 pods, respectively. With increase in temperature to $35 / 25^{\circ} \mathrm{C}$, the number of pods declined by $27 \%-35 \%$ in lentil genotypes, while chickpea genotypes were relatively unaffected (Table 3). With increase in temperature to $38 / 28^{\circ} \mathrm{C}$ and $40 / 30^{\circ} \mathrm{C}$, the number of pods decreased by $18 \%-25 \%$ and $38 \%-49 \%$ in chickpea, respectively, while lentil was inhibited by $38 \%-44 \%$ at $38 / 28^{\circ} \mathrm{C}$, and produced no pods at higher temperatures. When the temperature was raised to $42 / 32^{\circ} \mathrm{C}$, pods decreased severely $(72 \%-76 \%$ of control) in chickpea genotypes.

\subsection{3 | Seed yield/plant}

The seed yield ranged $5.13-5.98 \mathrm{~g} /$ plant in controls $\left(30 / 20^{\circ} \mathrm{C}\right)$ of chickpea genotypes and 2.19-2.31 g/plant in lentil genotypes. At $35 / 25^{\circ} \mathrm{C}$, seed yield was unaffected in chickpea genotypes, while it showed $9 \%-17 \%$ reduction in lentil genotypes (Table 3 ). At $38 / 28^{\circ} \mathrm{C}$, seed weight declined to $4.98-5.76 \mathrm{~g} / \mathrm{plant}$ (19\%-23\% of control) in chickpea and $1.87-1.98 \mathrm{~g} /$ plant $(33 \%-51 \%$ of control) in lentil genotypes. At $40 / 30^{\circ} \mathrm{C}$ and $42 / 32^{\circ} \mathrm{C}$, seed yield diminished to $3.14-3.62 \mathrm{~g} /$ plant $(31 \%-47 \%$ of the control) and $1.11-1.18 \mathrm{~g} /$ plant $(77 \%-81 \%$ of control) in chickpea genotypes, while lentil genotypes did not produce any pods and seeds, at these temperatures.

TAB LE 3 Growth and yield traits of chickpea (CP) and lentil (LT) genotypes at different high temperatures

\begin{tabular}{|c|c|c|c|c|c|}
\hline & $30 / 20^{\circ} \mathrm{C}$ & $35 / 25^{\circ} \mathrm{C}$ & $38 / 28^{\circ} \mathrm{C}$ & $40 / 30^{\circ} \mathrm{C}$ & $42 / 32^{\circ} \mathrm{C}$ \\
\hline CP-ICCV07110 & $6.68 \pm 0.82 \mathrm{Aa}$ & $7.13 \pm 0.76 \mathrm{Aa}$ & $5.29 \pm 0.82 \mathrm{CDa}$ & $5.12 \pm 0.36 \mathrm{CDa}$ & $3.43 \pm 0.24 \mathrm{Ea}$ \\
\hline CP-ICVV92944 & $6.89 \pm 0.84 \mathrm{Aa}$ & $7.28 \pm 0.82 \mathrm{Aa}$ & $5.45 \pm 0.69 \mathrm{CDa}$ & $4.87 \pm 0.33 \mathrm{DEa}$ & $3.24 \pm 0.28 \mathrm{Ea}$ \\
\hline CP-ICC5912 & $6.34 \pm 0.72 \mathrm{Aa}$ & $7.69 \pm 0.84 \mathrm{Aa}$ & $5.50 \pm 0.67 \mathrm{CDa}$ & $4.72 \pm 0.37 \mathrm{DEa}$ & $2.87 \pm 0.23 \mathrm{EFa}$ \\
\hline LT-LL699 & $6.13 \pm 0.80 \mathrm{Ba}$ & $5.69 \pm 0.83 \mathrm{Cb}$ & $3.82 \pm 0.66 \mathrm{~Eb}$ & $1.93 \pm 0.28 \mathrm{Cb}$ & $1.31 \pm 0.23 \mathrm{Fb}$ \\
\hline \multicolumn{6}{|l|}{ Pods (number/plant) } \\
\hline CP-ICCV07110 & $21.3 \pm 1.2 \mathrm{Db}$ & $19.6 \pm 1.2 \mathrm{Db}$ & $17.4 \pm 1.2 \mathrm{Db}$ & $13.2 \pm 1.3 \mathrm{Ea}$ & $5.5 \pm 0.76 \mathrm{Fa}$ \\
\hline CP-ICVV92944 & $18.9 \pm 1.4 \mathrm{Db}$ & $20.7 \pm 1.2 \mathrm{Db}$ & $19.2 \pm 1.2 \mathrm{Db}$ & $11.3 \pm 1.2 \mathrm{Ea}$ & $5.8 \pm 0.86 \mathrm{Fa}$ \\
\hline CP-ICC5912 & $20.5 \pm 1.4 \mathrm{Db}$ & $18.5 \pm 1.1 \mathrm{Db}$ & $15.4 \pm 1.5 \mathrm{DEb}$ & $10.3 \pm 1.2 \mathrm{EFa}$ & $4.8 \pm 0.87 \mathrm{Fa}$ \\
\hline CP-ICCV07110 & $5.98 \pm 0.76 \mathrm{Aa}$ & $5.76 \pm 0.74 \mathrm{Aa}$ & $4.59 \pm 0.65 \mathrm{ABa}$ & $3.09 \pm 0.32 \mathrm{Ba}$ & $1.14 \pm 0.22 \mathrm{Ba}$ \\
\hline CP-ICVV92944 & $5.27 \pm 0.67 \mathrm{Aa}$ & $5.19 \pm 0.73 \mathrm{Aa}$ & $4.23 \pm 0.55 \mathrm{ABa}$ & $2.89 \pm 0.40 \mathrm{Ba}$ & $1.11 \pm 0.23 \mathrm{Ba}$ \\
\hline CP-ICC5912 & $5.13 \pm 0.73 \mathrm{Aa}$ & $4.98 \pm 0.65 \mathrm{Aa}$ & $3.96 \pm 0.62 \mathrm{ABa}$ & $2.84 \pm 0.33 \mathrm{Ba}$ & $1.18 \pm 0.16 \mathrm{Ba}$ \\
\hline LT-LL699 & $2.19 \pm 0.72 \mathrm{Cb}$ & $1.98 \pm 0.64 \mathrm{Cb}$ & $1.06 \pm 0.31 \mathrm{Cb}$ & 0 & 0 \\
\hline LT-LL931 & $2.28 \pm 0.64 C b$ & $1.87 \pm 0.43 \mathrm{Cb}$ & $1.02 \pm 0.62 \mathrm{Cb}$ & 0 & 0 \\
\hline
\end{tabular}

Note: Mean values along with standard errors are presented. Different capital letters indicate significant differences $(p<.05)$ among genotypes of two species (as per nested ANOVA) across all the temperature treatments. Different small letters on bars indicate significant differences $(p<.05)$ between two species for a particular temperature. Measurements were recorded after 10 days of exposure to heat stress. 
A comparative table on the effects of heat stress for both the species indicating changes in different traits (in percentage) as well as days (for phenological traits) at various high temperatures over control is shown in Table 4.

Principal component analysis (PCA) was employed to summarise the information on large data set of multiple variables. In chickpea (Figure 8), based on principal component analysis, PC1 and PC2 explained the whole variability contributing $88.3 \%$ and $11.7 \%$, respectively. The most important traits for the separation were those with the biggest loading on $\mathrm{PC}_{1}$ and $\mathrm{PC}_{2}$. The largest group with positive loading on $\mathrm{PC}_{1}$ included biochemical traits viz., sucrose content, $\mathrm{H}_{2} \mathrm{O}_{2}$, SOD, CAT, APX and GR (0.124-0.205), whereas the largest negative loading was obtained mainly by reproductive (pollen viability, stigma receptivity), physiological (Chl content, $\mathrm{PE}$ ) and yield-related traits (pod setting, seed weight, pods/plant $\{(-0.205)-(-0.175)\}$. Similarly, $\mathrm{PC}_{2}$ revealed two groups of traits one with some phonological (DAP, DAM, PMI) and physiological traits (Chl, PE) loading positively (0.002-0.263), and the second one with physiological traits (Sc, RLWC, pollen germination) and yield-related traits (pods/ plant) loading negatively $\{(-0.8991)-(-0.9926)\}$. Biomass showed strong correlation with Rubisco, RLWC and PE, while seed yield correlated strongly with reproductive traits (pollen viability, pollen tube growth, stigma receptivity) and pods, flowering-podding interval (FPI), and physiological traits such as PE, chl and sucrose synthase (SS). Biomass and seed weight showed strong negative correlation with stomatal conductance $(\mathrm{Sc})$, oxidative molecules (MDA, $\mathrm{H}_{2} \mathrm{O}_{2}$ ) and antioxidative (SOD, CAT, APX, GR, ASC, GSH) molecules.

In lentil (Figure 9), PC1 and PC2 explained the whole variability contributing $87.3 \%$ and $12.7 \%$, respectively. The largest group with positive loading on $\mathrm{PC}_{1}$ included biochemical traits (sucrose content, $\mathrm{H}_{2} \mathrm{O}_{2}$, MDA, sucrose content), reproductive traits (pollen germination, pollen tube, stigma receptivity), yield traits (seed weight, seed setting) and phenological traits (days to podding and podding interval) with value ranging from 0.105 to 0.202 . On the other hand, the largest negative loading was obtained mainly by biochemical traits (SOD, CAT, APX, GR, GSH), physiological traits (RWLC, Chl, PE, SC, Rubisco) and yield trait (biomass) with value ranging from -0.202 to -0.194 . Similarly, $\mathrm{PC}_{2}$ explained reproductive traits (pollen germination, pollen tube, sigma receptivity), physiological (Chl content), yield trait (biomass) and biochemical traits (SOD, CAT, MDA, sucrose content, etc.) with loading positively (0.024-0.453). Biomass was strongly and positively correlated with Chl, RLWC, SS, Rubisco, Sc, PE and antioxidants such as GR, APX, CAT, SOD, GSH and ASC, while it showed negative correlation with oxidative molecules. Seed weight showed positive correlation with FPI, PMI, pod set and pod number and sucrose.

\section{DISCUSSION}

Heat stress could be a major factor affecting yield in cool-season legumes in the near future (Sita, Sehgal, HanumanthaRao, et al., 2017). Hence, it is vital to characterise the sensitivity of each food legume crop to high temperatures. In the present study, we evaluated the responses of few selective chickpea and lentil genotypes at the reproductive stage to the same degree of heat stress at varying high temperatures, under controlled environment, involving several traits (a comparative summary of the responses of both the crop species is shown in Table 4). Our previous studies (Awasthi et al., 2014; Sita, Sehgal, HanumanthaRao, et al., 2017) on these two crops, undertaken in natural outdoor conditions, indicated the drastic effects of high temperatures, especially above $35 / 25^{\circ} \mathrm{C}$ (day/night), on both the species. In the present study, we performed the experiments in growth chambers to test the comparative impacts of varying high temperatures $\left(35 / 25^{\circ} \mathrm{C}, 38 / 28^{\circ} \mathrm{C}, 40 / 30^{\circ} \mathrm{C}\right.$ and $42 / 32^{\circ} \mathrm{C}$ ) in both species, as well as to avoid any confounding effects, such as relative humidity, photoperiod and water stress, which might occur in the outdoor environment.

Comparative observations on phenology, biomass, reproductive and yield traits in the present study indicated that lentil was much more sensitive to temperatures above $35 / 25^{\circ} \mathrm{C}$ than chickpea; consequently, lentil showed greater reduction in yield than chickpea in all of the high-temperature treatments. Biomass showed drastic reduction at $38 / 28^{\circ} \mathrm{C}$ in both the species, which was associated with accelerated phenology (days to podding, flowering-podding and podding-maturity intervals) causing considerable reduction in yield traits. The decrease in biomass correlated with significant leaf damage and hence severe inhibition in photosynthetic ability in both the species, especially lentil, at $38 / 28^{\circ} \mathrm{C}$ and above. Heat stress is reported to induce earliness in reproductive stages in legumes (Sita, Sehgal, HanumanthaRao, et al., 2017), which seriously limits the potential production of pods and seeds. It was noticed that while lentil's growth and yield were inhibited significantly even at $35 / 25^{\circ} \mathrm{C}$, chickpea genotypes were not affected significantly until $38 / 28^{\circ} \mathrm{C}$ (Table 4), which matched the decrease in podding duration as well as pod set in our studies. Moreover, at higher temperatures $\left(40 / 30^{\circ} \mathrm{C}\right.$ and $42 / 32^{\circ} \mathrm{C}$ ), lentil genotypes suffered more yield reduction than chickpea genotypes, which was associated with more disruption in its (lentil) biomass. In previous studies too, high temperature inhibited the yield potential of chickpea (Devasirvatham et al., 2015) and lentil (Roy, Tarafdar, Das, \& Kundagrami, 2012) in studies performed on individual crops. Here, we report for the first time the differential sensitivity of these two cool-season legumes to high temperatures. At the same time, we also investigated the mechanisms related to these variations in heat sensitivity by examining reproductive and leaf function of both the crops.

Pod set, which is a major determinant of seed yield in legumes, depends on the successful completion of all reproductive events involving pollen development, pollen germination, pollen tube growth and fertilisation. Aberrations in any of these events would disrupt pod set. Reproductive function was assessed on the basis of various tests conducted on pollen grains. In general, these traits declined significantly as the temperature increased, more so in lentil genotypes than chickpea genotypes, indicating greater heat sensitivity of pollen and stigma function in the former species. Heat stress may inhibit pollen activity by influencing pollen grain development (Bishop, 
TAB LE 4 Comparative summary of various traits, as affected by increasing temperatures, in chickpea and lentil

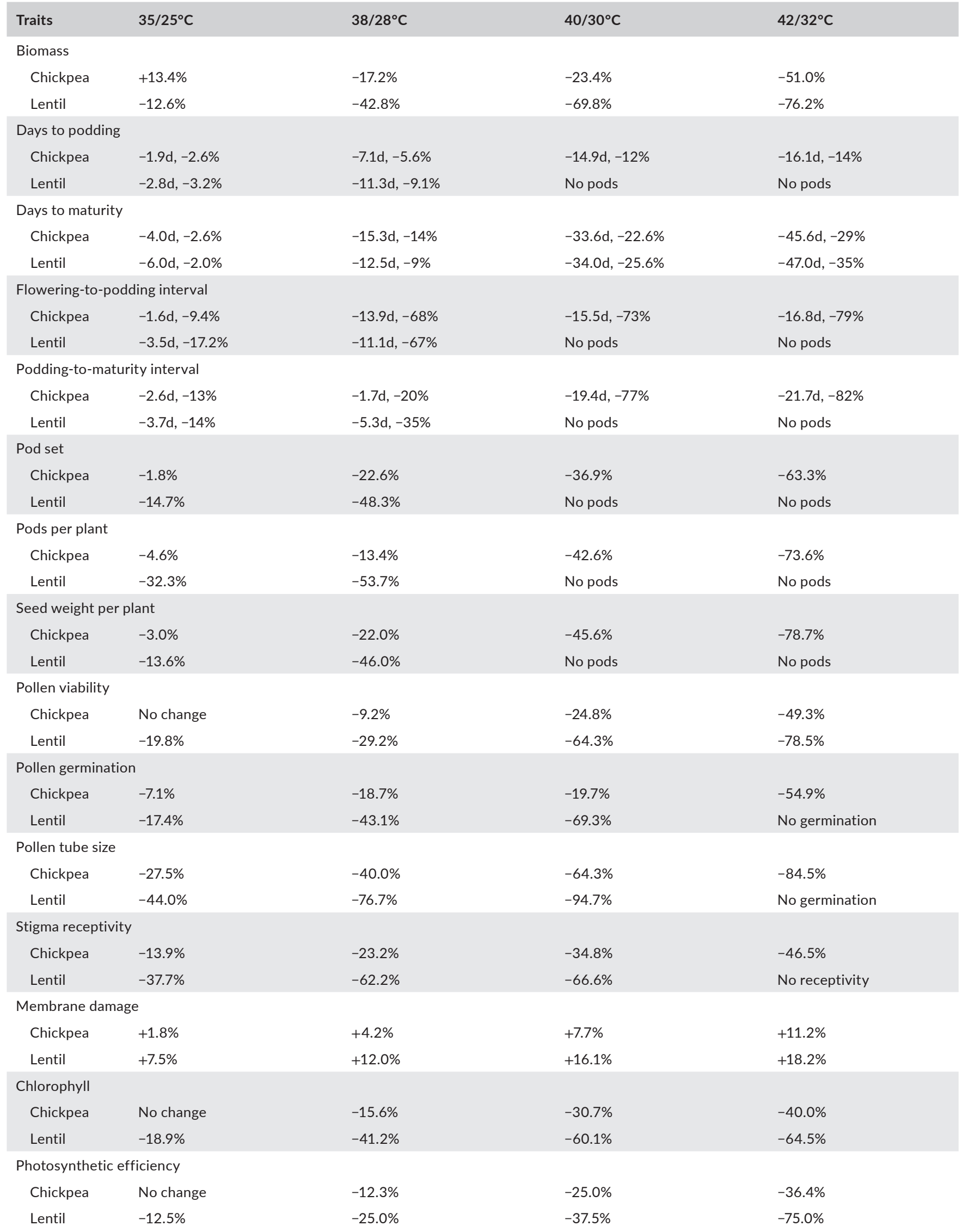


TABLE 4 (Continued)

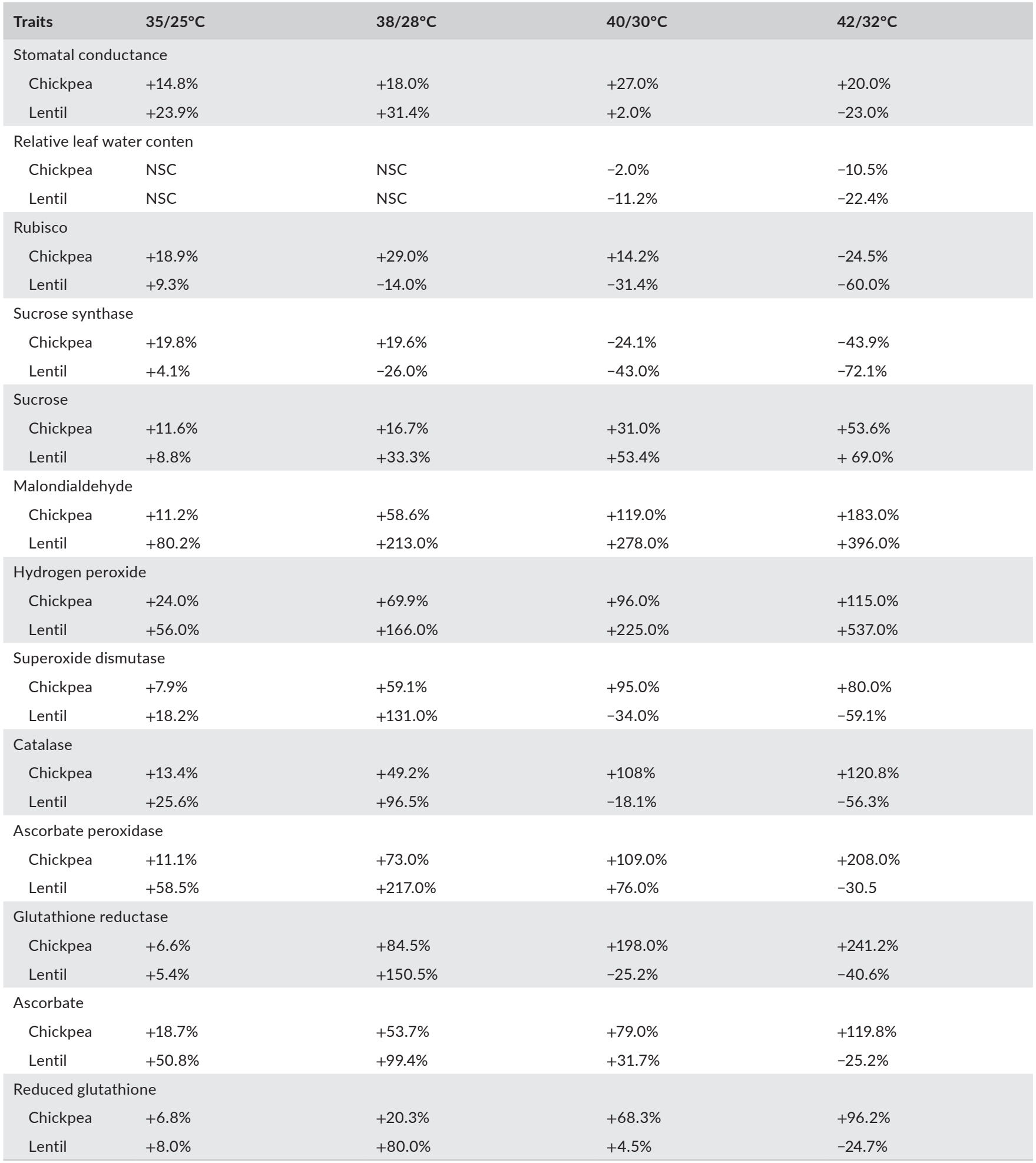

Note: The values indicate per cent change (- or + ) over control temperature $\left(30 / 20^{\circ} \mathrm{C}\right)$. In phenology-related traits, changes are also shown in days (d). Abberviation: NSC, no significant change.

Potts, \& Jones, 2016; Pressman, Peet, \& Pharr, 2002), endogenous levels of carbohydrates (Sato et al., 2006) and damage to the tapetum, epidermis, endothecium and stomium (Sakata \& Higashitani, 2008; Sato, Peet, \& Thomas, 2002). High temperatures may hinder pollen germination on the stigma surface due to loss of stigma receptivity as a result of the reduction in esterase activity (Hedhly, Hormaza, \& Herrero, 2005). In our studies, in vitro pollen tube growth was also retarded in heat-stressed plants, which might be attributed to reduced vigour due to reduced carbohydrate accumulation in pollen grains (Pressman et al., 2002) and/or the direct effects 


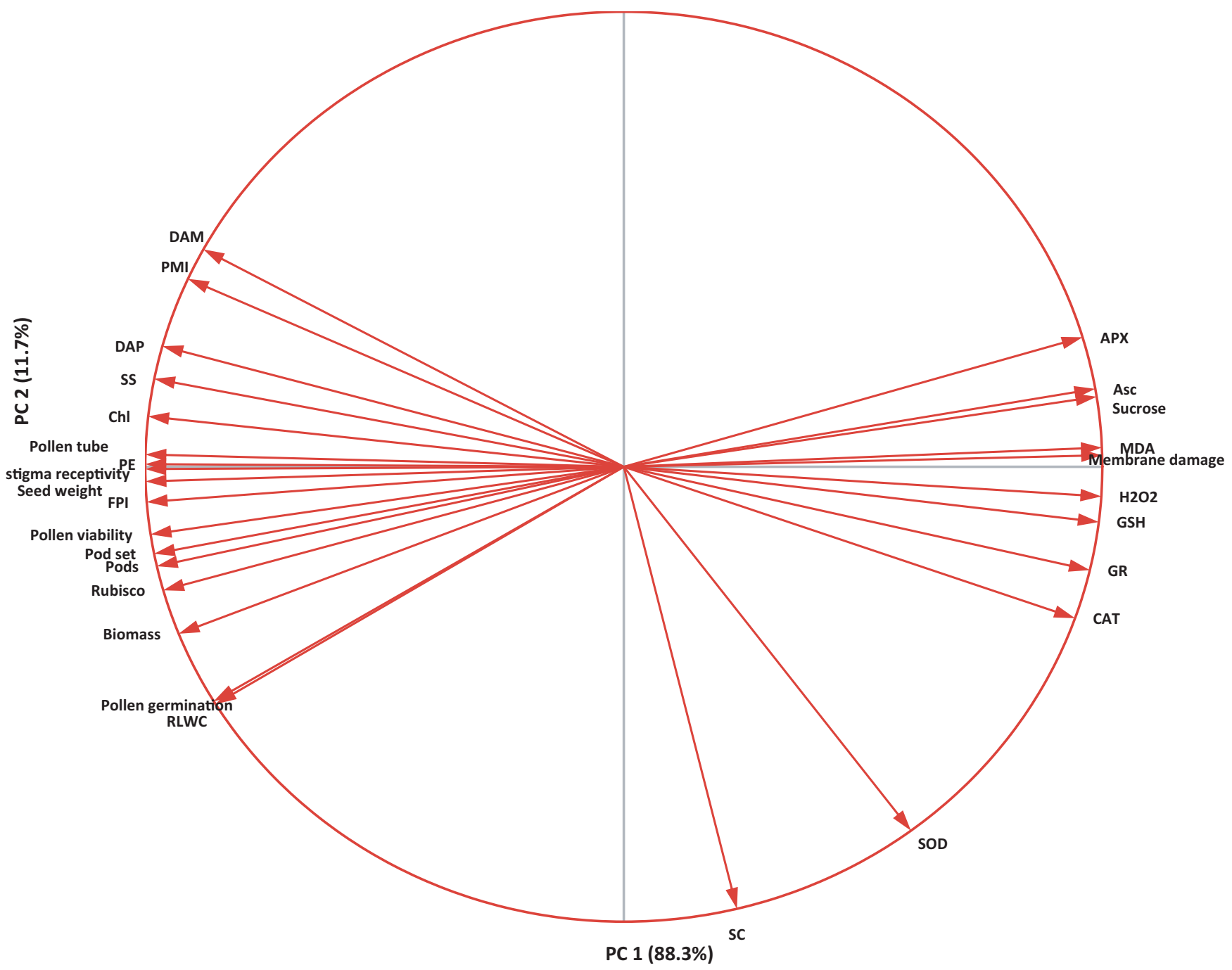

FIGURE 8 Principal component analysis (PCA) of percentage values about changes at high temperatures compared to control temperature $\left(30 / 20^{\circ} \mathrm{C}\right)$ in chickpea

of stressful temperatures on growth (Snider, Oosterhuis, Loka, \& Kawakami, 2011). Heat stress reduces carbohydrate accumulation in pollen grains and stigmatic tissue by altering assimilate partitioning (Kaushal et al., 2011), which might explain why pollen and stigmatic function declined in our study. In sorghum, heat stress reduced carbohydrate accumulation in pollen grains and ATP in stigmatic tissue (Jain, Prasad, Boote, Hartwell, \& Chourey, 2007), which affected reproductive function. Lentil genotypes showed lower temperature thresholds $\left(35 / 25^{\circ} \mathrm{C}\right)$ for reproductive function; the podding duration and pod set were significantly less in lentil genotypes than chickpea genotypes at these temperatures, which correlated with greater damage to reproductive function in lentil.

\section{1 | Water relations and tissue damage}

Leaves act as sources of carbohydrates for the developing reproductive structures; hence, maintenance of their function under heat stress is vital. One of the primary effects of heat stress is on leaf water status, which did not change significantly in chickpea or lentil up to $38 / 28^{\circ} \mathrm{C}$ but declined at higher temperatures $\left(40 / 30^{\circ} \mathrm{C}\right.$ and $42 / 32^{\circ} \mathrm{C}$ ), more so in lentil than chickpea. Heat stress can affect the hydraulics of roots and the stem (Wahid et al., 2007) to decrease water absorption and hence leaf water content. Stomatal conductance (gs) increased in both species to a variable extent up to $38 / 28^{\circ} \mathrm{C}$-which possibly contributed to an increase in transpiration to reduce leaf temperature-but decreased at $40 / 30^{\circ} \mathrm{C}$ in lentil, which correlated with a marked reduction in its leaf water content. At $42 / 32^{\circ} \mathrm{C}$, the decrease in gs was associated with a reduction in RLWC in both species, more so in lentil, which accentuated the damage to leaves and reproductive function since heat, in combination with water stress, is more detrimental than either stress alone (Awasthi et al., 2014).

The damage to leaf tissue was measured with membrane damage as electrolyte leakage test, which increased as the temperature increased, less so in chickpea than in lentil genotypes, thus corroborating latter's greater heat sensitivity. Previously, heat sensitivity in food legumes (Srinivasan, Takeda, \& Senboku, 1996) and other crops 


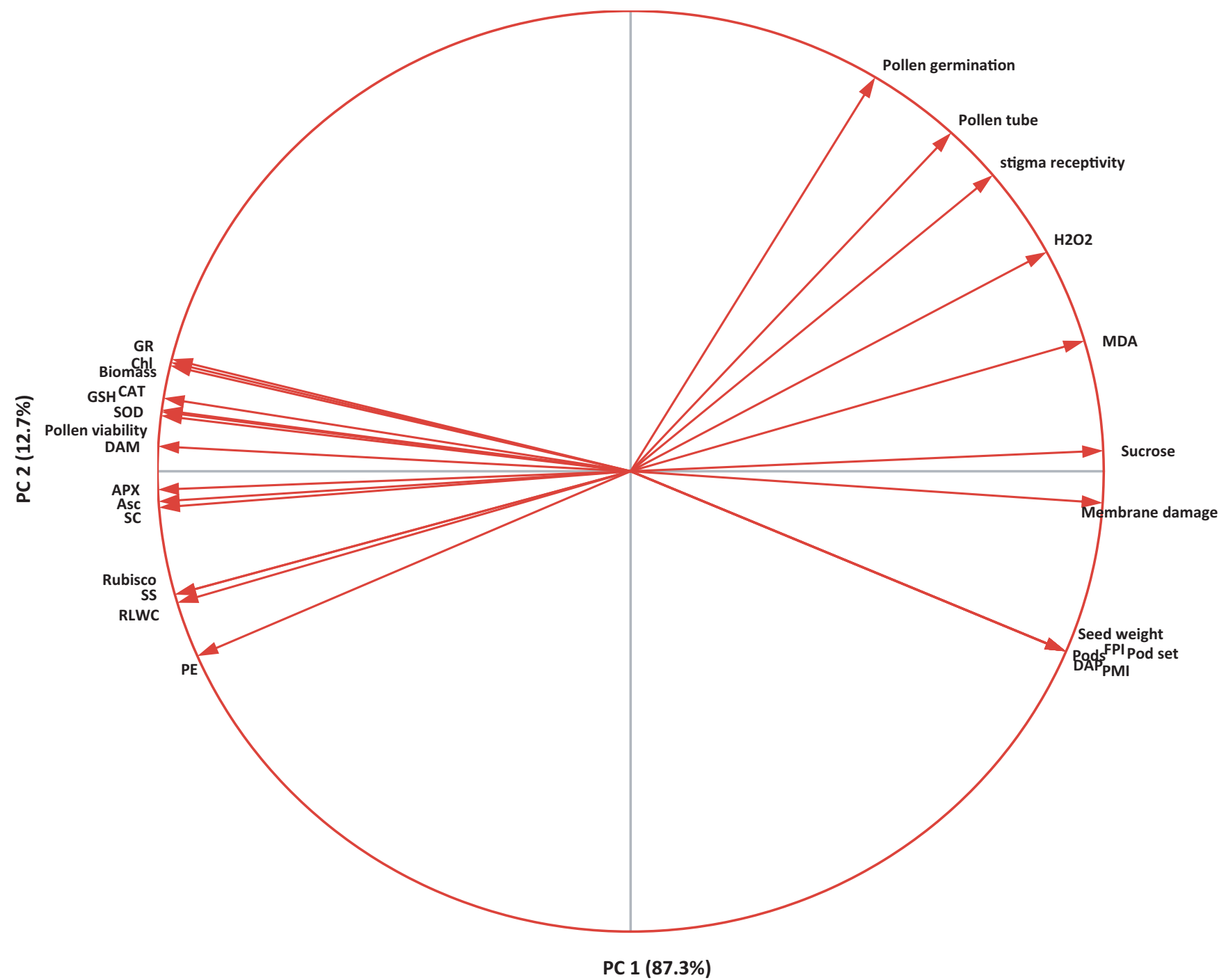

FIGURE 9 Principal component analysis (PCA) of percentage values about changes at high temperatures compared to control temperature $\left(30 / 20^{\circ} \mathrm{C}\right)$ in lentil

(Dias, Barreiro, Campos, Ramalho, \& Lidon, 2010) was reported to correlate with membrane damage. Membrane damage was evident in lentil even at $35 / 25^{\circ} \mathrm{C}$, but at higher temperatures in chickpea. At $42 / 32^{\circ} \mathrm{C}$, membrane damage was highest and likely due to the combined effects of heat and water stress (Awasthi et al., 2014). Heat stress is known to cause membrane damage and hence a reliable indicator of heat sensitivity in plants (Gulen \& Eris, 2004; Liu \& Huang, 2000). The results of this study indicate that leaf tissue in lentil is significantly more sensitive to heat stress than chickpea.

\subsection{Carbon fixation and sucrose metabolism}

Photosynthetic function-assessed by measuring Pn, chlorophyll concentration, photosynthetic efficiency (PE), Rubisco (carbonfixing enzyme), sucrose synthase activity and sucrose concentration-decreased in both species to a variable extent in response to high-temperature stress. As the temperature increased above
$35 / 25^{\circ} \mathrm{C}$, the chlorophyll concentration decreased significantly, particularly in lentil genotypes. Chlorophyll loss may be due to the direct effect of heat stress on chloroplast membranes (Kotak et al., 2007) and is similar to observations on heat-stressed wheat (Almeselmani, Deshmukh, \& Sairam, 2009), tomato (Camejo \& Torres, 2001) and rice (Sohn \& Back, 2007). Inhibited biosynthesis or degradation of chlorophyll (Tewari \& Tripathy, 1998) and/ or disorganisation of chloroplasts due to photooxidation (Camejo et al., 2006), as a result of heat stress, might reduce chlorophyll concentration. Along with the reduction in chlorophyll concentration, $\mathrm{PE}$ also declined in both species, similar to findings in tomato (Willits \& Peet, 2001), but not as much in chickpea genotypes at all high temperatures. A previous report suggested that heattolerant common bean genotypes maintain higher PE than their counterparts (Petkova, Denev, Cholakov, \& Porjazov, 2007). The photosystem II (PSII) complex is thermally labile and considered the most heat-sensitive component of the electron transport chain (Almeselmani, Deshmukh, \& Kushwaha, 2009; Havaux \& Tardy, 
1996; Yamane, Shikanai, Kashino, Koike, \& Satoh, 2000). In spinach, high temperature caused cross-linking of the D1 protein with D2 protein, resulting in a dramatic decrease in PSII yield (Ohira \& Yamamoto, 2001).

The activity of Rubisco, the first enzyme of the Calvin cycle, decreased in a temperature-dependent manner in both species, especially in lentil genotypes at all temperatures. Calvin cycle reactions are more sensitive to heat stress than PSII electron transport. The primary site of inhibition of the Calvin cycle under high temperature appears to be Rubisco activation via Rubisco activase, as reported in wheat (Law \& Crafts-Brandner, 1999). As the temperature increases, Rubisco activase becomes less effective in maintaining Rubisco in a catalytically active state (Salvucci \& Crafts-Brandner, 2004b), which may have occurred in this study. The reduction in Rubisco activity in the leaves of heatstressed plants implies a decline in carboxylation capacity as a result of damage to photosynthetic apparatus (Sainz, Diaz, Monza, \& Borsani, 2010) or direct inhibition of this enzyme (Salvucci \& Crafts-Brandner, 2004a; Wang et al., 1992). In this context, higher Rubisco activity in chickpea than lentil genotypes during heat stress possibly helps to maintain better photosynthetic function to sustain sucrose production and support reproductive function as well, resulting in higher number of filled pods in chickpea. Inhibition of Rubisco activity is likely to influence sucrose production due to limitations in the availability of hexoses.

Sustaining sucrose levels in leaves is critical during stressed conditions. The sucrose concentration in leaves of heat-stressed plants declined in both crops, more so in lentil, which was correlated with a decrease in the activity of the sucrose synthesising enzyme, sucrose synthase, as reported previously (Kaushal et al., 2011). A reduction in sucrose concentration in leaves restricts its availability to the developing reproductive components (Kaushal et al., 2011; Snider et al., 2011) and hence explains the disruptions in reproductive function (Sita, Sehgal, HanumanthaRao, et al., 2017). Development of pollen grains and the sustenance of pollen function are linked to carbohydrate availability to flowers, which is affected under heat stress (Kaushal et al., 2011; Pressman et al., 2002). In sorghum, heat stress, especially during the night, was reported to inhibit the photosynthetic function in leaves to interrupt pollen function (Jain et al., 2007; Prasad \& Djanaguiraman, 2011; Snider et al., 2011). Thus, in our studies, the accessibility of carbohydrates was restricted more in lentil, than in chickpea, which explained more damage to reproductive function and pod set.

\section{3 | Oxidative damage and antioxidants}

This comparative study indicated more oxidative damage to leaves of lentil genotypes, which appeared prominently at $35 / 25^{\circ} \mathrm{C}$ and intensified further with increasing temperature. Previous studies have indicated that heat-sensitive species (e.g., Brassica; Wilson, Sangha, Banga, Atwal, \& Gupta, 2014; Kentucky bluegrass; Li, Zhan, Xu, Han, \& Zhang, 2014, Chickpea; Kaushal et al., 2013) and their genotypes show marked increase in malondialdehyde (MDA) and hydrogen peroxide concentration under heat stress-an indicator of damage due to reactive oxygen species (ROS) - which may have been associated with more injury to membranes and chlorophyll in lentil at $35 / 25^{\circ} \mathrm{C}$ and above.

To manage oxidative damage by ROS induced by heat stress, cells up-regulate diverse enzymatic and non-enzymatic antioxidants (Awasthi et al., 2015). We assessed the activity profiles of some of these enzymes (superoxide dismutase [detoxifies superoxides], catalase [detoxifies hydrogen peroxide], ascorbate peroxidase [detoxifies hydrogen peroxide], glutathione reductase [detoxifies hydrogen peroxide, along with APX in ascorbate-glutathione pathway]) as well as some non-enzymes (ascorbate and reduced glutathione), and found marked variations in their expression patterns in both the crop types. Lentil up-regulated these antioxidants at $35 / 25^{\circ} \mathrm{C}$, which subsequently declined markedly as the temperature increased that might have resulted in increased ROS to intensify the oxidative damage. The inhibition of various antioxidants at high temperature in lentil might occur due to denaturation of the proteins (Bita \& Gerats, 2013), thus impairing its ability to manage the ROS effectively causing more damage to various leaf traits. At the same time, chickpea genotypes relatively maintained higher expression of these antioxidants, resulting in a reduced amount of oxidative damage, and hence less injury to membranes. Thus, variation in the expression profiles of these antioxidants might be a vital reason at the cellular level in causing more damage to leaves by heat stress to lentil genotypes than chickpea genotypes. Earlier studies on various plant species and their genotypes, contrasting in heat sensitivity, have also reported that heat tolerance was associated with higher activity expression of various antioxidants, for example in cereals (Kumar, Gupta, \& Nayyar, 2012), chickpea (Kumar et al., 2013) and lentil (Sita, Sehgal, Kumar, et al., 2017).

PCA revealed that sustenance of the biomass under heat stress was strongly correlated with photosynthetic function (comprising of chlorophyll, PS II function, Rubisco activity), while seed number was positively correlated with various reproductive traits (such as pollen viability, pollen tube growth, stigma receptivity), flowering-podding interval (FPI), sucrose synthase and sucrose concentration, which might provide some useful leads on subsequent studies on heat response of legumes.

The present study indicated that lentil gets inhibited even at $35 / 25^{\circ} \mathrm{C}$, while chickpea showed significant heat damage at temperatures exceeding $38 / 28^{\circ} \mathrm{C}$ suggesting more sensitivity of the former to heat stress. The greater heat sensitivity in lentil may be due to faster acceleration of its phenology, reduced biomass coupled with poor ability to manage ROS, which resulted in more damage to cell membranes and chlorophyll, and thus impaired its photosynthetic ability to produce less sucrose. Consequently, the deprivation of sucrose resulted in lesser biomass in lentil, which also contributed towards poor reproductive function and pod set, resulting in more yield reduction in lentil than in chickpea genotypes. 


\section{ACKNOWLEDGEMENTS}

The authors are thankful for financial assistance from DST, India (PURSE funding), ICARDA Morocco (from CRP-GLDC), and The University of Western Australia, Perth, Australia.

\section{AUTHORS' CONTRIBUTION}

$\mathrm{KB}, \mathrm{KS}, \mathrm{AS}$ and $\mathrm{AB}$ were involved in conducting the experiments at various stages. PG, SK and SS contributed towards providing the chickpea and lentil germplasm for the experiments and assisted in compilation and interpretation of results. KHMS, PVVP, UJ and HN were involved in analysis, writing and editing the Ms.

\section{ORCID}

P. V. Vara Prasad iD https://orcid.org/0000-0001-6632-3361

Harsh Nayyar (iD https://orcid.org/0000-0001-6005-4391

\section{REFERENCES}

Alexander, M. P. (1969). Differential staining of aborted and nonaborted pollen. Stain Technology, 44,117-122. https://doi.org/10.3109/10520 296909063335

Almeselmani, M., Deshmukh, P. S., \& Kushwaha, S. R. (2009). Effect of heat stress on wheat: Physiological aspects and yield. In Crop production under diverse environments. Jaipur, India: Pointer Publishers.

Almeselmani, M., Deshmukh, P., \& Sairam, R. (2009). High temperature stress tolerance in wheat genotypes: Role of antioxidant defence enzymes. Acta Agronomica Hungarica, 57, 1-14. https://doi. org/10.1556/AAgr.57.2009.1.1

Annisa, A., Chen, S., Turner, N. C., \& Cowling, W. A. (2013). Genetic variation for heat tolerance during the reproductive phase in Brassica rapa. Journal of Agronomy and Crop Science, 199(6), 424-435. https:// doi.org/10.1111/jac.12034

Arnon, D. I. (1949). Copper enzymes in isolated chloroplasts. Polyphenoloxidase in Beta vulgaris. Plant Physiology, 24, 1.

Awasthi, R., Bhandari, K., \& Nayyar, H. (2015). Temperature stress and redox homeostasis in agricultural crops. Frontiers in Environmental Science, 3, 1-24. https://doi.org/10.3389/fenvs.2015.00011

Awasthi, R., Kaushal, N., Vadez, V., Turner, N. C., Berger, J., Siddique, K. H., \& Nayyar, H. (2014). Individual and combined effects of transient drought and heat stress on carbon assimilation and seed filling in chickpea. Functional Plant Biology, 41, 1148-1167. https://doi. org/10.1071/FP13340

Barnabás, B., Jäger, K., \& Fehér, A. (2008). The effect of drought and heat stress on reproductive processes incereals. Plant, Cell and Environment, 31, 11-38. https://doi.org/10.1111/j.1365-3040.2007.01727.x

Barrs, H. D., \& Weatherley, P. E. (1962). A re-examination of the relative turgidity technique for estimating water deficits in leaves. Australian Journal of Biological Sciences, 15, 413-428. https://doi.org/10.1071/ B19620413

Bishop, J., Potts, S. G., \& Jones, H. E. (2016). Susceptibility of faba bean (Vicia faba L.) to heat stress during floral development and anthesis. Journal of Agronomy and Crop Science, 202, 508-517. https://doi. org/10.1111/jac.12172

Bita, C., \& Gerats, T. (2013). Plant tolerance to high temperature in a changing environment: Scientific fundamentals and production of heat stress-tolerant crops. Frontiers in Plant Science, 4, 1-18. https:// doi.org/10.3389/fpls.2013.00273

Brewbaker, J. L., \& Kwack, B. H. (1963). The essential role of calcium ion in pollen germination and pollen tube growth. American Journal of Botany, 50, 859-865. https://doi.org/10.2307/2439772

Camejo, D., Jiménez, A., Alarcón, J. J., Torres, W., Gómez, J. M., \& Sevilla, F. (2006). Changes in photosynthetic parameters and antioxidant activities following heat-shock treatment in tomato plants. Functional Plant Biology, 33, 177-187.

Camejo, D., \& Torres, W. (2001). High temperature effect on tomato (Lycopersicon esculentum) pigment and protein content and cellular viability. Cultivos Tropicales, 22, 13-17.

Devasirvatham, V., Gaur, P. M., Raju, T. N., Trethowan, R. M., \& Tan, D. K. Y. (2015). Field response of chickpea (Cicer arietinum L.) to high temperature. Field Crops Research, 172, 59-71. https://doi.org/10.1016/j. fcr.2014.11.017.

Dhindsa, R. S., Plumb-Dhindsa, P., \& Thorpe, T. A. (1981). Leaf senescence: Correlated with increased levels of membrane permeability and lipid peroxidation, and decreased levels of superoxide dismutase and catalase. Journal of Experimental Botany, 32, 93-101. https://doi. org/10.1093/jxb/32.1.93.

Dias, A. S., Barreiro, M. G., Campos, P. S., Ramalho, J. C., \& Lidon, F. C. (2010). Wheat cellular membrane thermotolerance under heat stress. Journal of Agronomy and Crop Science, 196(2), 100-108. https://doi. org/10.1111/j.1439-037X.2009.00398.x

Gaur, P. M., Samineni, S., Krishnamurthy, L., Varshney, R. K., Kumar, S., Ghanem, M. E., ... Nayyar, H. (2014). High temperature tolerance in grain legumes. Legume Perspectives, 7, 23-24.

Giorno, F., Wolters-Arts, M., Mariani, C., \& Rieu, I. (2013). Ensuring reproduction at high temperatures: The heat stress response during anther and pollen development. Plants, 2, 489-506. https://doi. org/10.3390/plants2030489

Griffith, O. W. (1980). Determination of glutathione and glutathione disulfide using glutathione reductase and 2-vinylpyridine. Analytical Biochemistry, 106(1), 207-212. https://doi.org/10.1016/00032697(80)90139-6

Gulen, H., \& Eris, A. (2004). Effect of heat stress on peroxidase activity and total protein content in strawberry plants. Plant Science, 166, 739-744. https://doi.org/10.1016/j.plantsci.2003.11.014

Hasanuzzaman, M., Nahar, K., Alam, M. M., Roychowdhury, R., \& Fujita, M. (2013). Physiological, biochemical, and molecular mechanisms of heat stress tolerance in plants. International Journal of Molecular Sciences, 14, 9643-9968. https://doi.org/10.3390/ijms14059643

Havaux, M., \& Tardy, F. (1996). Temperature-dependent adjustment of the thermal stability of photosystem II in vivo: Possible involvement of xanthophyll-cycle pigments. Planta, 198, 324-333.

Hawker, J. S., Walker, R. R., \& Ruffner, H. P. (1976). Invertase and sucrose synthase in flowers. Phytochemistry, 15, 1441-1444.

Heath, R. L., \& Packer, L. (1968). Photoperoxidation in isolated chloroplasts: I. Kinetics and stoichiometry of fatty acid peroxidation. Archives of Biochemistry and Biophysics, 125, 189-198. https://doi. org/10.1016/0003-9861(68)90654-1

Hedhly, A., Hormaza, J. I., \& Herrero, M. (2005). Influence of genotype-temperature interaction on pollen performance. Journal of Evolutionary Biology, 18(6), 1494-1502. https://doi. org/10.1111/j.1420-9101.2005.00939.x

Jain, M., Prasad, P. V., Boote, K. J., Hartwell, A. L., \& Chourey, P. S. (2007). Effects of season-long high temperature growth conditions on sugar-to-starch metabolism in developing microspores of grain sorghum (Sorghum bicolor L. Moench). Planta, 227, 67-79. https://doi. org/10.1007/s00425-007-0595-y

Jones, M. G., Outlaw, W. H., \& Lowry, O. H. (1977). Enzymic assay of $10^{-7}$ to $10^{-14}$ moles of sucrose in plant tissues. Plant Physiology, 60, 379-383. 0.1104/pp.60.3.379

Kaushal, N., Awasthi, R., Gupta, K., Gaur, P., Siddique, K. H., \& Nayyar, H. (2013). Heat-stress-induced reproductive failures in chickpea (Cicer arietinum) are associated with impaired sucrose metabolism in leaves and anthers. Functional Plant Biology, 40, 1334-1349. https://doi. org/10.1071/FP13082

Kaushal, N., Gupta, K., Bhandhari, K., Kumar, S., Thakur, P., \& Nayyar, H. (2011). Proline induces heat tolerance in chickpea (Cicer arietinum L.) plants by protecting vital enzymes of carbon and antioxidative 
metabolism. Physiology and Molecular Biology of Plants, 17, 203-213. https://doi.org/10.1007/s12298-011-0078-2

Kotak, S., Larkindale, J., Lee, U., von Koskull-Döring, P., Vierling, E., \& Scharf, K. D. (2007). Complexity of the heat stress response in plants. Current Opinion in Plant Biology, 10, 310-316. https://doi. org/10.1016/j.pbi.2007.04.011

Kumar, S., Gupta, D., \& Nayyar, H. (2012). Comparative response of maize and rice genotypes to heat stress: Status of oxidative stress and antioxidants. Acta Physiologiae Plantarum, 34, 75-86. https://doi. org/10.1007/s11738-011-0806-9

Kumar, S., Thakur, P., Kaushal, N., Malik, J. A., Gaur, P., \& Nayyar, H. (2013). Effect of varying high temperatures during reproductive growth on reproductive function, oxidative stress and seed yield in chickpea genotypes differing in heat sensitivity. Archives of Agronomy and Soil Science, 59, 823-843. https://doi.org/10.1080/03650340.2012.683424

Law, R., \& Crafts-Brandner, S. J. (1999). Inhibition and acclimation of photosynthesis to heat stress is closely correlated with activation of ribulose-1,5-bisphosphate carboxylase/oxygenase. Plant Physiology, 120, 173-182. https://doi.org/10.1104/pp.120.1.173

Li, F., Zhan, D., Xu, L., Han, L., \& Zhang, X. (2014). Antioxidant and hormone responses to heat stress in two Kentucky bluegrass cultivars contrasting in heat tolerance. Journal of American Society for Horticultural Science, 139, 587-596. https://doi.org/10.21273/ JASHS.139.5.587

Liu, X., \& Huang, B. (2000). Heat stress injury in relation to membrane lipid peroxidation in creeping bentgrass. Crop Science, 40, 503-510. https://doi.org/10.2135/cropsci2000.402503x

Lutts, S., Kinet, J. M., \& Bouharmont, J. (1996). NaCl-induced senescence in leaves of rice (Oryza sativa L.) cultivars differing in salinity resistance. Annals of Botany, 78, 389-398. https://doi.org/10.1006/ anbo.1996.0134

Mattson, O., Knox, R. B., Heslop-Harrison, J., \& Heslop-Harrison, Y. (1974). Protein pellicle of stigmatic papillae as a probable recognition site in incompatibility reactions. Nature, 247, 298-300. https://doi. org/10.1038/247298a0

Mavis, R. D., \& Stellwagen, E. (1968). Purification and subunit structure of glutathione reductase from bakers' yeast. Journal of Biological Chemistry, 243, 809-814.

Mukherjee, S. P., \& Choudhuri, M. A. (1983). Implications of water stress-induced changes in the levels of endogenous ascorbic acid and hydrogen peroxide in Vigna seedlings. Physiologia Plantarum, 58, 166-170. https://doi.org/10.1111/j.1399-3054.1983.tb04162.x

Nakano, Y., \& Asada, K. (1981). Hydrogen peroxide is scavenged by ascorbate-specific peroxidase in spinach chloroplasts. Plant and Cell Physiology, 22, 867-880. https://doi.org/10.1093/oxfordjournals. pcp.a076232

Ohira, S., \& Yamamoto, Y. (2001). Heat stress and light stress cooperatively damage the D1 protein in PS II. Science Access, 3, 1-4. https:// doi.org/10.1071/SA0403231

Petkova, V., Denev, I. D., Cholakov, D., \& Porjazov, I. (2007). Field screening for heat tolerant common bean cultivars (Phaseolus vulgaris L.) by measuring of chlorophyll fluorescence induction parameters. Scientia Horticulturae, 111, 101-106. https://doi.org/10.1016/j.scien ta.2006.10.005

Prasad, P. V., \& Djanaguiraman, M. (2011). High night temperature decreases leaf photosynthesis and pollen function in grain sorghum. Functional Plant Biology, 38, 993-1003. https://doi.org/10.1071/ FP11035

Pressman, E., Peet, M. M., \& Pharr, D. M. (2002). The effect of heat stress on tomato pollen characteristics is associated with changes in carbohydrate concentration in the developing anthers. Annals of Botany, 90, 631-636. https://doi.org/10.1093/aob/mcf240

Racker, E. (1962). Ribulose diphosphate carboxylase from spinach leaves: Ribulose diphosphate $+\mathrm{CO}_{2}+\mathrm{H}_{2} \mathrm{O} \rightarrow 2$ 3-P-Glycerate. In Methods in enzymology (Vol. 5, pp. 266). New York, NY: Academic Press.
Roy, C. D., Tarafdar, S., Das, M., \& Kundagrami, S. (2012). Screening lentil (Lens culinaris Medik) germplasms for heat tolerance. Trends in Biosciences, 5, 143-146.

Sainz, M., Diaz, P., Monza, J., \& Borsani, O. (2010). Heat stress results in loss of chloroplast $\mathrm{Cu} / \mathrm{Zn}$ superoxide dismutase and increased damage to Photosystem II in combined drought-heat stressed Lotus japonicus. Physiologia Plantarum, 140, 46-56. https://doi. org/10.1111/j.1399-3054.2010.01383.x

Sakata, T., \& Higashitani, A. (2008). Male sterility accompanied with abnormal anther development in plants-genes and environmental stresses with special reference to high temperature injury. International Journal of Plant Developmental Biology, 2, 42-48.

Salvucci, M. E., \& Crafts-Brandner, S. J. (2004a). Inhibition of photosynthesis by heat stress: The activation state of Rubisco as a limiting factor in photosynthesis. Physiologia Plantarum, 120, 179-186. https:// doi.org/10.1111/j.0031-9317.2004.0173.x

Salvucci, M. E., \& Crafts-Brandner, S. J. (2004b). Relationship between the heat tolerance of photosynthesis and the thermal stability of Rubisco activase in plants from contrasting thermal environments. Plant physiology, 134, 1460-1470.

Sato, S., Kamiyama, M., Iwata, T., Makita, N., Furukawa, H., \& Ikeda, H. (2006). Moderate increase of mean daily temperature adversely affects fruit set of Lycopersicon esculentum by disrupting specific physiological processes in male reproductive development. Annals of Botany, 97, 731-738. https://doi.org/10.1093/aob/mcl037

Sato, S., Peet, M. M., \& Thomas, J. F. (2002). Determining critical pre- and post-anthesis periods and physiological processes in Lycopersicon esculentum Mill. exposed to moderately elevated temperatures. Journal of Experimental Botany, 53, 1187-1195. https://doi.org/10.1093/ jexbot/53.371.1187

Sehgal, A., Sita, K., Siddique, K. H., Kumar, R., Bhogireddy, S., Varshney, R. K., ... Nayyar, H. (2018). Drought or/and heat-stress effects on seed filling in food crops: Impacts on functional biochemistry, seed yields, and nutritional quality. Frontiers in Plant Science, 9, 1-19. https://doi. org/10.3389/fpls.2018.01705

Sharma, D. K., Andersen, S. B., Ottosen, C. O., \& Rosenqvist, E. (2015). Wheat cultivars selected for high Fv/Fm under heat stress maintain high photosynthesis, total chlorophyll, stomatal conductance, transpiration and dry matter. Physiologia Plantarum, 153, 284-298. https://doi.org/10.1111/ppl.12245

Sita, K., Sehgal, A., HanumanthaRao, B., Nair, R. M., Vara Prasad, P. V., Kumar, S., ... Nayyar, H. (2017). Food legumes and rising temperatures: Effects, adaptive functional mechanisms specific to reproductive growth stage and strategies to improve heat tolerance. Frontiers in Plant Science, 8, 1-30. https://doi.org/10.3389/fpls.2017.01658

Sita, K., Sehgal, A., Kumar, J., Kumar, S., Singh, S., Siddique, K. H. M., \& Nayyar, H. (2017). Identification of high-temperature tolerant lentil (Lens culunaris Medik.) genotypes through leaf and pollen traits. Frontiers in Plant Science, 8, 1-27. https://doi.org/10.3389/ fpls.2017.00744

Snider, J. L., Oosterhuis, D. M., Loka, D. A., \& Kawakami, E. M. (2011). High temperature limits in vivo pollen tube growth rates by altering diurnal carbohydrate balance in field-grown Gossypium hirsutum pistils. Journal of Plant Physiology, 168, 1168-1175. https://doi. org/10.1016/j.jplph.2010.12.011

Sohn, S. O., \& Back, K. (2007). Transgenic rice tolerant to high temperature with elevated contents of dienoic fatty acids. Biologia Plantarum, 51, 340-342.

Srinivasan, A., Saxena, N. P., \& Johansen, C. (1999). Cold tolerance during early reproductive growth of chickpea (Cicer arietinum L.): Genetic variation in gamete development and function. Field Crops Research, 60, 209-222. https://doi.org/10.1016/S0378-4290(98)00126-9

Srinivasan, A., Takeda, H., \& Senboku, T. (1996). Heat tolerance in food legumes as evaluated by cell membrane thermostability and chlorophyll fluorescence techniques. Euphytica, 88, 35-45. 
Stone, P. J. (2001). The effects of heat stress on cereal yield and quality. In A. S. Basra (Ed.), Crop responses and adaptations to temperature stress (pp. 243-291). New York, NY: Food products Press.

Teranishi, Y., Tanaka, A., Osumi, M., \& Fukui, S. (1974). Catalase activities of hydrocarbon-utilizing Candida yeasts. Agricultural and Biological Chemistry, 38, 1213-1220. https://doi.org/10.1080/00021 369.1974.10861301

Tewari, A. K., \& Tripathy, B. C. (1998). Temperature-stress-induced impairment of chlorophyll biosynthetic reactions in cucumber and wheat. Plant Physiology, 117, 851-858. https://doi.org/10.1104/ pp.117.3.851

Wahid, A., Gelani, S., Ashraf, M., \& Foolad, M. R. (2007). Heat tolerance in plants: An overview. Environmental and Experimental Botany, 61, 199-223. https://doi.org/10.1016/j.envexpbot.2007.05.011

Wang, Z. Y., Snyder, G. W., Esau, B. D., Portis, A. R., \& Ogren, W. L. (1992). Species dependent variation in the interaction of substrate-bound ribulose-1,5-bisphosphate carboxylase/oxygenase (Rubisco) and Rubisco activase. Plant Physiology, 100, 1858-1862. https://doi. org/10.1104/pp.100.4.1858

Wardlaw, I. F., \& Wrigley, C. (1994). Heat tolerance in temperate cereals: An overview. Australian Journal of Plant Physiology, 21, 695-703.

Willits, D. H., \& Peet, M. M. (2001). Measurement of chlorophyll fluorescence as a heat stress indicator in tomato: Laboratory and greenhouse comparisons. Journal of the American Society for Horticultural Science, 126, 188-194. https://doi.org/10.21273/JASHS.126.2.188

Wilson, R. A., Sangha, M. K., Banga, S. S., Atwal, A. K., \& Gupta, S. (2014). Heat stress tolerance in relation to oxidative stress and antioxidants in Brassica juncea. Journal of Environmental Biology, 35, 383.
Yamane, Y., Shikanai, T., Kashino, Y., Koike, H., \& Satoh, K. (2000). Reduction of QA in the dark: Another cause of fluorescence Fo increases by high temperatures in higher plants. Photosynthesis Research, 63, 23-34.

Yang, H., Gu, X., Ding, M., Lu, W., \& Lu, D. (2018). Heat stress during grain filling affects activities of enzymes involved in grain protein and starch synthesis in waxy maize. Scientific Reports, 8, 15665. https:// doi.org/10.1038/s41598-018-33644-z

Zhou, R., Kjaer, K. H., Rosenqvist, E., Yu, X., \& Ottosen, C. O. (2016). Physiological response to heat stress during seedling and anthesis stage in tomato genotypes differing in heat tolerance. Journal of Agronomy and Crop Science, 203(1), 68-80. https://doi.org/10.1111/ jac.12166

How to cite this article: Bhandari K, Sita K, Sehgal A, et al. Differential heat sensitivity of two cool-season legumes, chickpea and lentil, at the reproductive stage, is associated with responses in pollen function, photosynthetic ability and oxidative damage. J Agro Crop Sci. 2020;00:1-25. https://doi. org/10.1111/jac.12433 